\title{
Impact of multiple radar reflectivity data assimilation on the numerical simulation of a flash flood event during the HyMeX campaign
}

\author{
Ida Maiello ${ }^{1,2}$, Sabrina Gentile ${ }^{3,1}$, Rossella Ferretti ${ }^{2}$, Luca Baldini $^{4}$, Nicoletta Roberto ${ }^{4}$ Errico Picciotti $^{2,5}$, \\ Pier Paolo Alberoni ${ }^{6}$, and Frank Silvio Marzano ${ }^{1,2}$ \\ ${ }^{1}$ Department of Information Engineering, Electronics and Telecommunications, Sapienza University of Rome, \\ Rome, Italy \\ ${ }^{2}$ CETEMPS, Department of Physical and Chemical Sciences, University of L'Aquila, L'Aquila, Italy \\ ${ }^{3}$ Institute of Methodologies for Environmental Analysis, CNR IMAA, Potenza, Italy \\ ${ }^{4}$ Institute of Atmospheric Sciences and Climate, CNR ISAC, Rome, Italy \\ ${ }^{5}$ Himet s.r.l., L'Aquila, Italy \\ ${ }^{6}$ Arpae Emilia Romagna, Servizio Idro-Meteo-Clima, Bologna, Italy \\ Correspondence to: Ida Maiello (ida.maiello@aquila.infn.it)
}

Received: 23 June 2016 - Discussion started: 15 July 2016

Revised: 19 August 2017 - Accepted: 26 September 2017 - Published: 7 November 2017

\begin{abstract}
An analysis to evaluate the impact of multiple radar reflectivity data with a three-dimensional variational (3-D-Var) assimilation system on a heavy precipitation event is presented. The main goal is to build a regionally tuned numerical prediction model and a decision-support system for environmental civil protection services and demonstrate it in the central Italian regions, distinguishing which type of observations, conventional and not (or a combination of them), is more effective in improving the accuracy of the forecasted rainfall. In that respect, during the first special observation period (SOP1) of HyMeX (Hydrological cycle in the Mediterranean Experiment) campaign several intensive observing periods (IOPs) were launched and nine of which occurred in Italy. Among them, IOP4 is chosen for this study because of its low predictability regarding the exact location and amount of precipitation. This event hit central Italy on 14 September 2012 producing heavy precipitation and causing several cases of damage to buildings, infrastructure, and roads. Reflectivity data taken from three C-band Doppler radars running operationally during the event are assimilated using the 3-D-Var technique to improve high-resolution initial conditions. In order to evaluate the impact of the assimilation procedure at different horizontal resolutions and to assess the impact of assimilating reflectivity data from multiple radars, several experiments using the Weather Research
\end{abstract}

and Forecasting (WRF) model are performed. Finally, traditional verification scores such as accuracy, equitable threat score, false alarm ratio, and frequency bias - interpreted by analysing their uncertainty through bootstrap confidence intervals (CIs) - are used to objectively compare the experiments, using rain gauge data as a benchmark.

\section{Introduction}

In the last few years, a large number of floods caused by different meteorological events have occurred in Italy. These events mainly affected small areas (few hundreds of square kilometres) making their forecast very difficult. Indeed, one of the most important factors in producing a flash flood was found to be the persistence of the meteorological system over the same area in the presence of specific hydrological conditions (the size and the topography of the drainage basin, the amount of urban use within the basin, and so on), allowing for the accumulation of a large amount of rain (Doswell et al., 1996). In complex orography areas, such the Italian regions, this is largely due to the barrier effect produced by the mountains, such as the Apennines. Moreover, the Mediterranean Basin is affected by a complex meteorology, due to 
the peculiar distribution of land and water, and due to the Mediterranean Sea temperature, which is warmer than that of the European northern seas (Baltic Sea and North Sea). These factors can produce severe meteorological events: for example, if precipitation persists over urbanized watersheds with steep slopes, devastating floods can occur in a relatively short time.

The scientific community widely recognizes the need for numerical weather prediction (NWP) models to be run at high resolution for improving very short-term quantitative precipitation forecasts (QPFs) during severe weather events and flash floods. The combination of NWP models and weather radar observations has shown improved skill with respect to extrapolation-based techniques (Sun et al., 2014). Nevertheless, the accuracy of the mesoscale NWP models is negatively affected by the "spin-up" effect (Daley, 1991) and is mostly dependent on the errors in the initial and lateral boundary conditions (IC and BC, respectively), along with deficiencies in the numerical models themselves, and at the resolution of kilometres are even more critical because of the lack of high-resolution observations, apart from radar data. Several studies in the meteorological field have demonstrated that the assimilation of appropriate data into the NWP models, especially radar (Sugimoto et al., 2009) and satellite ones (Sokol, 2009), significantly reduces the "spin-up" effect and improves the IC and BC of the mesoscale models. Classical observations such as TEMP (upper-level temperature, humidity, and wind observations) or SYNOP (surface synoptic observations) do not have enough density to describe for example local convection, while radar measurements can provide a sufficient density of data. Maiello et al. (2014) showed the positive effect of the assimilation of radar data into the precipitation forecast of a heavy rainfall event occurring in central Italy. The authors showed the improvement gained by using assimilated radar data rather than a conventional approach. Similar results are obtained for a case of severe convective storm in Croatia by Stanesic and Brewste (2016).

Weather radar has a fundamental role in showing tridimensional structures of convective storms and the associated mesoscale and microscale systems (Nakatani, 2015). As an example, Xiao and Sun (2007) showed that the assimilation of radar observation at high resolution $(2 \mathrm{~km})$ can improve the prediction of convective systems. Recent research in meteorology has established that the assimilation of realtime data, especially radar measurements (radial velocities and/or reflectivities), into the mesoscale NWP models can improve predicted precipitations for the next few hours (e.g. Xiao et al., 2005; Sokol and Rezacova, 2006; Dixon et al., 2009; Salonen et al., 2010).

The aim of this study is to investigate the potential of improving NWP rainfall forecasts by assimilating multiple radar reflectivity data in combination or not with conventional observations. This may also have a direct benefit for hydrological applications, particularly for real-time flash flood prediction and consequently for civil protection pur- poses. Major obstacles, which make the assimilation of radar reflectivities into NWP models a challenging problem both mathematically and physically, lie in the nonlinear relationship between radar reflectivity and precipitation intensity as well as in the rapid evolution of mesoscale systems. While the radial velocities observation operator is linear and based directly on prognostic model variables (i.e. wind), the assimilation of radar reflectivity is more challenging than radial velocity, because the observation operator of radar reflectivity is highly nonlinear and has a non-Gaussian error probability density function.

The novelty of the paper is in exploring the impact on the high-resolution forecast of the assimilation of multiple radar reflectivity data in a complex orography area, such as central Italian regions, to predict intense precipitation. This aim is reached by using the IOP4 of the SOP1 in the framework of the HyMeX campaign (Ducrocq et al., 2014; Ferretti et al., 2014; Davolio et al., 2015). The SOP1 was held from 5 September to 5 November 2012; the IOP4 was issued for the central Italy target area on 14 September 2012 and it was tagged both as a heavy precipitation event (HPE) and a flash flood event (FFE). The reflectivity measured by three C-band weather radars was ingested together with traditional meteorological observations (SYNOP and TEMP) using 3-D-Var to improve the WRF model performance. So far, several studies about reflectivity data assimilation in heavy rainfall cases have been performed (e.g. Ha et al., 2011; Das et al., 2015) also including data of multiple radars and in complex orography (e.g. Lee et al., 2010; Liu et al., 2013). However, this is the first experiment conducted on the Italian territory taking advantage of the reflectivity data collected by all the radars that cover central Italy.

The paper is arranged as follows. Section 2 provides information on the FFE and WRF model configuration. Section 3 presents the observations to be assimilated, the WRF 3-D-Var data assimilation system, and the evaluation method used. The results are presented and assessed in Sects. 4 and 5. Summary and conclusions are given in the final section.

\section{Study area and model setup}

Flash floods are still one of the natural hazards producing human and economic losses (Llasat et al., 2013). Moreover, an increasing trend of the occurrence of severe events in the whole Mediterranean area has been found by several authors (Hertig et al., 2012; Martin et al., 2013; Diodato and Bellocchi, 2014). These open issues drove the HyMeX programme (http://www.hymex.org) aiming at a better understanding of the water cycle in the Mediterranean with a focus on extreme weather events. The observation strategy of $\mathrm{HyMeX}$ is organized into long-term (4 years) enhanced observation periods (EOPs) and short-term (2 months) special observation periods (SOPs). During the SOP1, which was held from 5 September to 5 November 2012 with the ma- 

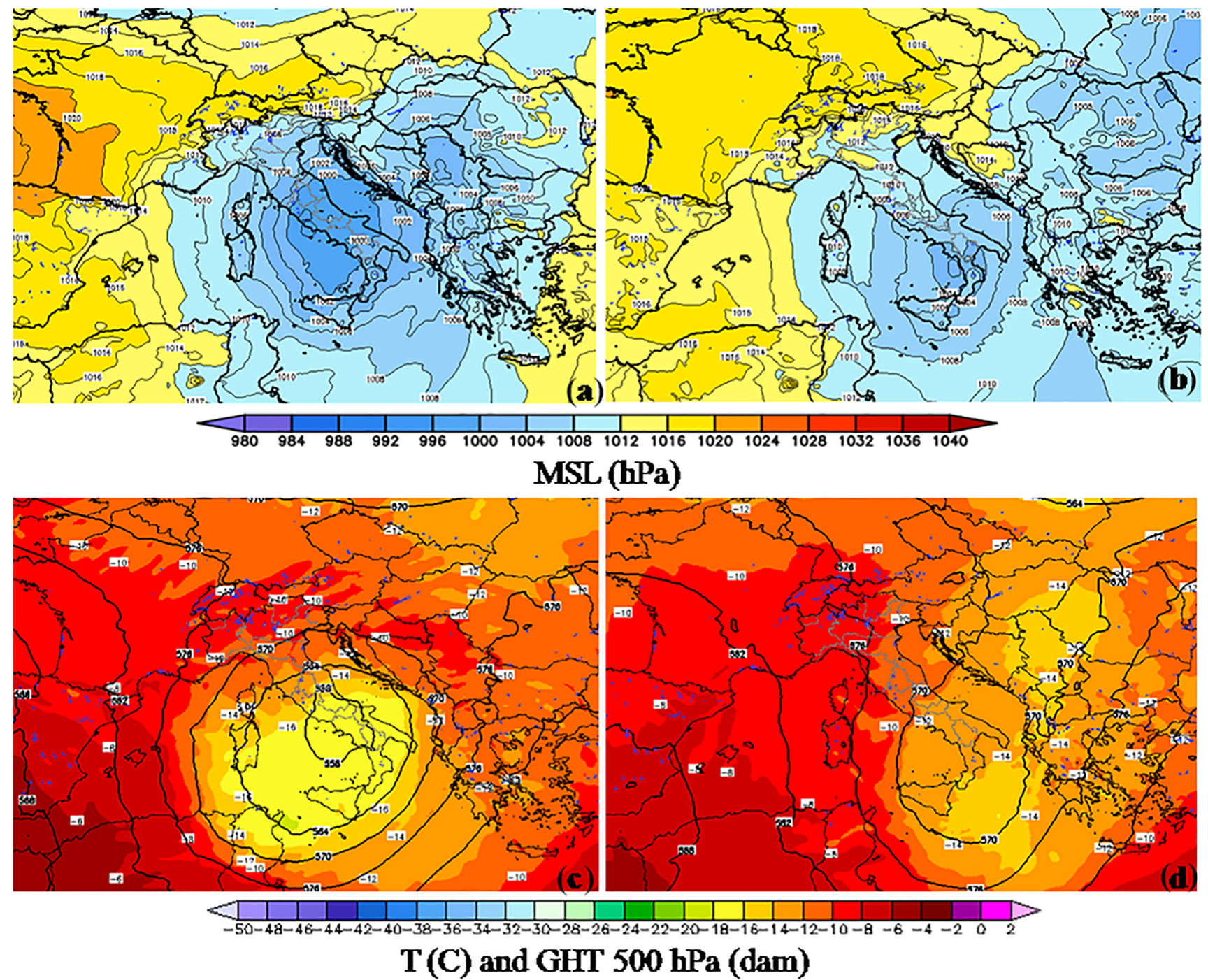

Figure 1. ECMWF (European Centre for Medium-Range Weather Forecasts) analyses at 12:00 UTC on 14 September 2012: (a) mean sea level pressure and (c) temperature (colour shades) and geopotential height (black isolines) at 500 hPa; ECMWF analyses at 12:00 UTC on 15 September 2012: (b) mean sea level pressure and (d) temperature (colour shades) and geopotential height (black isolines) at $500 \mathrm{hPa}$.

jor aim of investigating still-unclear mesoscale meteorological mechanisms over the Mediterranean area, three Italian hydro-meteorological sites were identified within the western Mediterranean target area (TA): Liguria-Tuscany (LT), northeastern Italy (NEI), and central Italy (CI). Several intensive observing periods (IOPs) were issued during the campaign to document HPEs, FFEs, and orographic precipitation events (ORPs).

\subsection{Case study}

During the day of 14 September 2012 a deep upper-level trough entered the Mediterranean Basin and deepened over the Tyrrhenian Sea slowly moving southeastward. A cutoff low developed over central Italy (Fig. 1a and c) advect- ing cold air along the central Adriatic coast producing instability over central and southern Italy, and enhanced the Bora flow over the northern Adriatic Sea. Convection with heavy precipitations occurred in the morning of 14 September mainly along the central eastern Italian coast (Marche and Abruzzo regions), associated with the cut-off low over the Tyrrhenian Sea, producing flood in the urban area of Pescara (central western coast of Abruzzo region) where rainfall reached $150 \mathrm{~mm}$ in a few hours causing several river overflows, a landslide, and much damage in the area of the city hospital. Progressive motion southeastward of the cutoff and its filling (Fig. 1b and d) gradually moved phenomena over the south of Italy, even if some instability still remained over the mid-Adriatic until the afternoon of Saturday 15 September. At the same time, a high-pressure ridge de- 


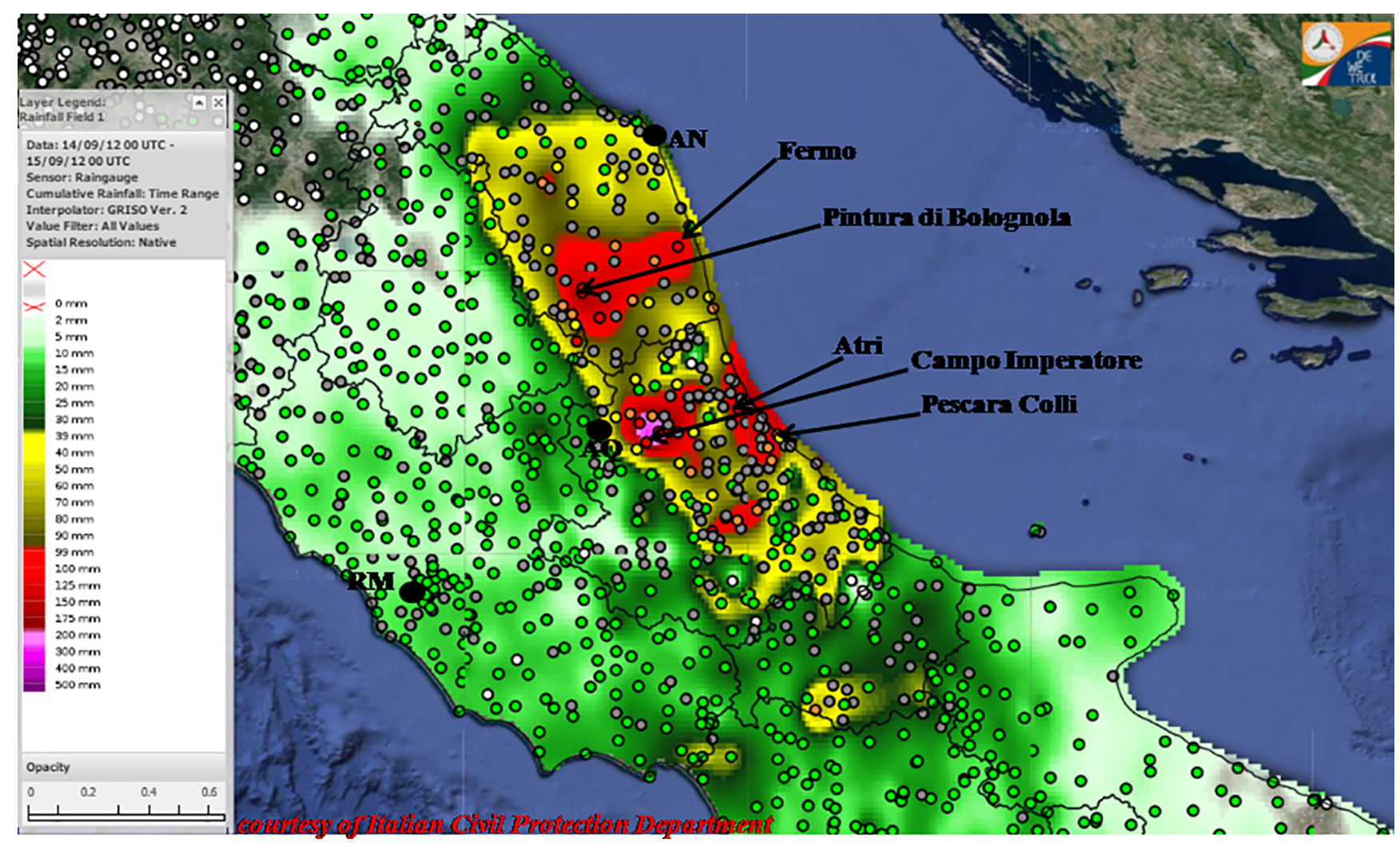

Figure 2. Interpolated map of $24 \mathrm{~h}$ accumulated rainfall from 00:00 UTC on 14 September 2012 over Abruzzo and Marche regions taken from the DEWETRA system from rain gauge measurements. Black contours are the administrative boundaries of regions, while the coloured circles represent the warning pluviometric thresholds.

veloped in the western part of the western Mediterranean domain; this ridge slowly drifts eastwards during the weekend.

Figure 2, produced using the DEWETRA operational platform, shows the interpolated map of $24 \mathrm{~h}$ accumulated rainfall recorded from the rain gauge network from 14 September to 15 September (00:00-00:00 UTC) with a maximum accumulated rainfall on the highest peak of the Abruzzo region (Campo Imperatore) reaching approximately $300 \mathrm{~mm}$ in $24 \mathrm{~h}$. DEWETRA (Italian Civil Protection Department, CIMA Research Foundation, 2014) is an operational web platform used by the Italian Civil Protection Department (DPC) and implemented by CIMA Research Foundation (http://www.cimafoundation.org/en/). DEWETRA allows the synthesis, integration, and comparison of information necessary for instrumental monitoring and model forecasting, and to construct real-time risk scenarios and their possible evolution. Rain gauge time series of some selected stations in the Marche and Abruzzo regions, where the most significant amount of rainfall accumulated, are presented in Fig. 3: Fermo and Pintura di Bolognola (Marche region), respectively, with nearly $130 \mathrm{~mm}$ in $24 \mathrm{~h}$ (Fig. 3a) and $180 \mathrm{~mm}$ in $24 \mathrm{~h}$ (Fig. 3b); Campo Imperatore, Atri, and Pescara Colli (Abruzzo region) with respectively nearly $300 \mathrm{~mm}$ (Fig. 3c), $160 \mathrm{~mm}$ (Fig. 3d), and $140 \mathrm{~mm}$ (Fig. 3e) in $24 \mathrm{~h}$. It is clearly shown (Fig. 3) that the accumulation started around 02:00 UTC on 14 September: in Fermo, Atri and Pescara Colli most of rainfall was concentrated in the first half of the day, whereas in Pintura di Bolognola and Campo Imperatore, precipitation fell all day long. The large amount of hourly precipitation for Atri and Pescara Colli, respectively, at 06:00 UTC and 05:00 UTC (red ovals in Fig. 3d and e) reached $45 \mathrm{mmh}^{-1}$, indicating convective precipitation, whereas rainfall at Campo Imperatore rain gauge (Fig. 3c) was much weaker but lasting longer, reaching an accumulated amount of approximately $300 \mathrm{~mm}$ in $24 \mathrm{~h}$.

Figure 4 shows the vertical maximum intensity (VMI) reflectivity product from the Italian radar network (Vulpiani et al., 2008a) superimposed onto the Meteosat second generation (MSG) $10.8 \mu \mathrm{m}$ image (in normalized inverted greyscale). A close-up over the central Italy target area highlights a line of convective cells along the Apennines in central Italy due to the western flow approaching the orographic barrier. VMI values above $45 \mathrm{dBZ}$ are associated with intense precipitation that occurred during convective events. 


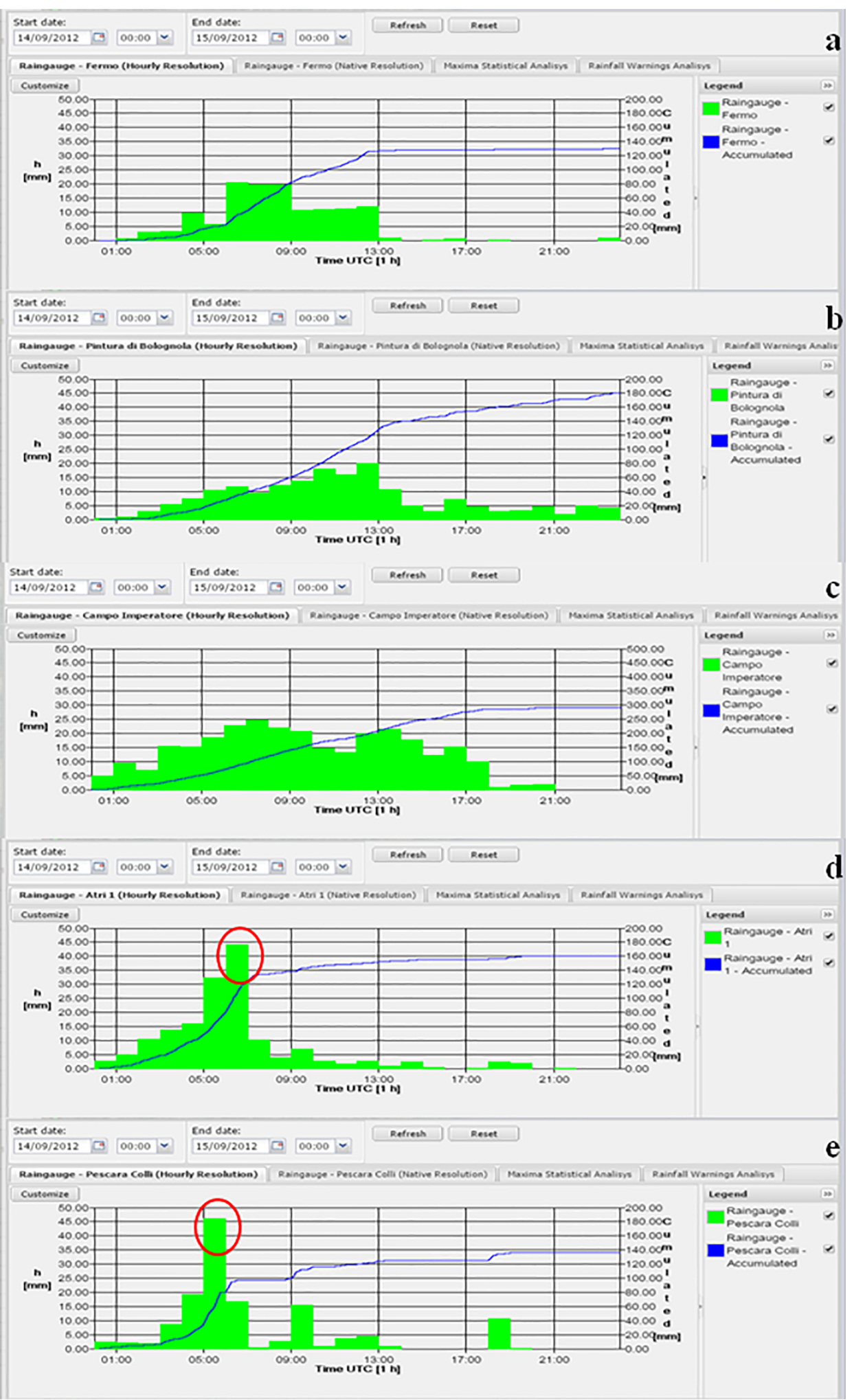

Figure 3. Rain gauge time series of some selected stations in Marche (a, Fermo; b, Pintura di Bolognola) and Abruzzo (c, Campo Imperatore; d, Atri; and e, Pescara Colli) regions during the event of 14 September 2012. The green histogram represents the hourly accumulated precipitation (scale on the left); the blue line represents the incremental accumulation within the $24 \mathrm{~h}$ (scale on the right). (Courtesy of Italian Civil Protection Department.) 


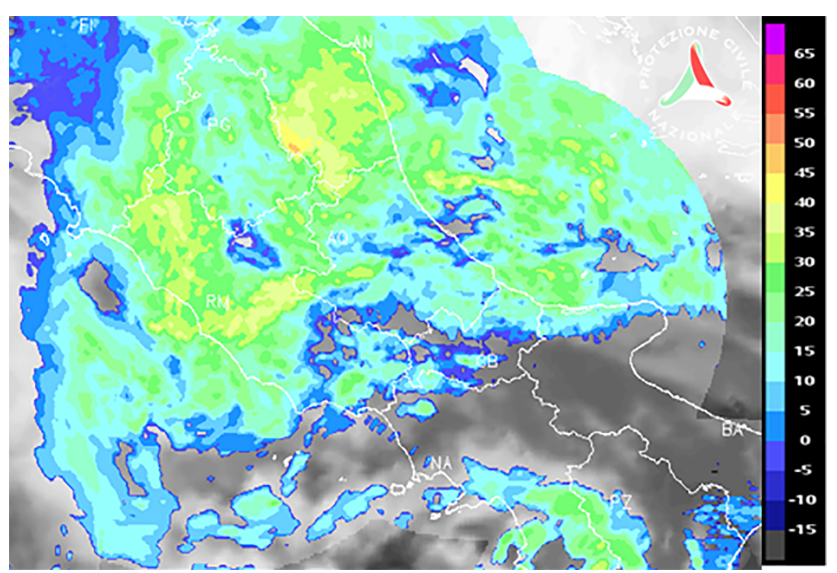

Figure 4. Close-up over central Italy of the reflectivity on 14 September 2012 at 08:00 UTC from the Italian radar network overlapped with the MSG (IR 10.8) at 07:30 UTC. (Courtesy of Italian DPC.)

\subsection{WRF model setup}

The numerical weather prediction experiments are performed in this work using the non-hydrostatic Advanced Research WRF (ARW) modelling system V3.4.1. It is a primitive equations mesoscale meteorological model, with terrainfollowing vertical coordinates and options for different physical parameterizations. Skamarock et al. (2008) provide a detailed overview of the model.

In this study, a one-way nested configuration using the ndown program is used: a $12 \mathrm{~km}$ domain $(263 \times 185)$ that covers central Europe and the western Mediterranean Basin (referred to as D01) is initialized using the European Centre for Medium-Range Weather Forecasts (ECMWF) analyses at $0.25^{\circ}$ horizontal resolution; an innermost domain that covers the whole of Italy (referred to as D02), with a grid space of $3 \mathrm{~km}(445 \times 449)$ using as BC and IC the output of the previous forecast at $12 \mathrm{~km}$. Both domains run with 37 unequally spaced vertical levels, from the surface up to $100 \mathrm{hPa}$ (Fig. 5).

Taking into account that the performance of a mesoscale model is highly related to the parameterization schemes, the main physics packages used in this study are set as for the operational configuration (Ferretti et al., 2014) used at the Centre of Excellence CETEMPS (http://cetemps.aquila.infn.it/). They include (Skamarock et al., 2008): the "New" Thompson et al., 2004, microphysics scheme, the MYJ (MellorYamada-Janjić) scheme for the PBL (planetary boundary layer), the Goddard shortwave radiation scheme and the RRTM (rapid radiative transfer model) longwave radiation scheme, the Eta similarity scheme for surface layer formulation and the Noah LSM (land surface model) to parameterize the physics of land surface. A few preliminary tests are performed to assess the best cumulus parameterization scheme to be used both for the coarse and finest resolution domain for this event. Hence, the following parameterizations are tested:

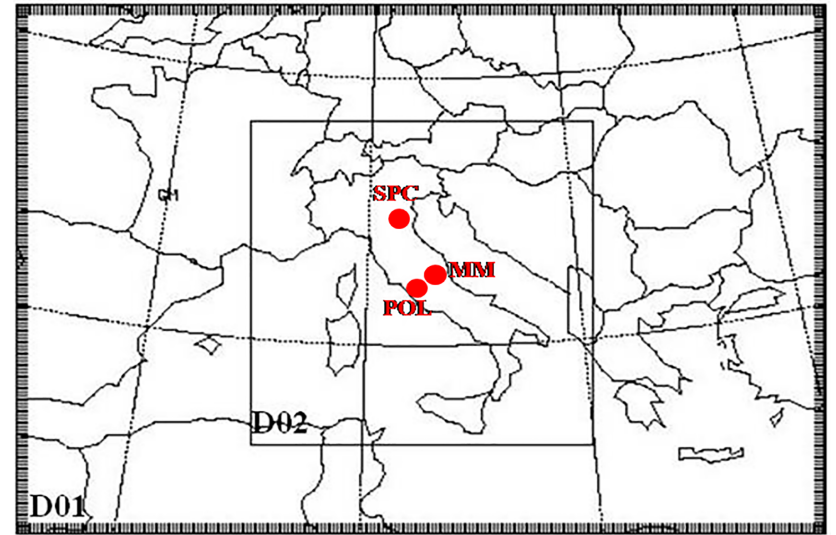

Figure 5. WRF ndown domain configuration: the two domains have resolution of 12 and $3 \mathrm{~km}$, respectively. The high-resolution D02 over Italy includes Mt Midia (MM), ISAC-CNR (P55C) and San Pietro Capofiume (SPC) radars (red dots in the figure).

the new Kain-Fritsch and the Grell 3-D schemes. The latter is an enhanced Dudhia of the Grell-Deveneyi scheme, in our simulations only used on the lowest resolution domain, where the option cugd_avedx (subsidence spreading) is switched on. Based on the results of these two cumulus parameterization schemes, the one producing the best precipitation forecast will be used to evaluate the impact of data assimilation.

\section{Data and methodology}

This section is focused on the description of types of observations ingested into the assimilation procedure, namely both conventional and radar, and on the 3-D-Var methodology as well as the observation operator used for the calculation of the reflectivity. Also, a brief overview of the evaluation method adopted to assess the performance of numerical weather predictions will be given.

\subsection{Observations to be assimilated}

Conventional observations SYNOP and TEMP were retrieved from the ECMWF Meteorological Archival and Retrieval System (MARS). They have been packed in a suitable format for incorporation into the assimilation procedure using the Observation Preprocessor (OBSPROC) module provided by the 3-D-Var system. Among its main functions are to perform a quality control check and to assign observational errors based on a pre-specified error file. In short, a total of 983 observations (967 SYNOP and 16 TEMP) are incorporated into the coarse-resolution domain, whereas a total of 338 (333 SYNOP and 5 TEMP) observations are incorporated into the high-resolution one. 
Table 1. Technical characteristics of the three radars whose reflectivity have been assimilated during IOP4.

\begin{tabular}{|c|c|c|c|c|}
\hline Features & Units & $\begin{array}{l}\text { MM } \\
\text { radar }\end{array}$ & $\begin{array}{l}\mathrm{P} 55 \mathrm{C} \\
\text { radar }\end{array}$ & $\begin{array}{l}\text { SPC } \\
\text { radar }\end{array}$ \\
\hline Owner & & $\begin{array}{l}\text { CF Abruzzo } \\
\text { Region }\end{array}$ & $\begin{array}{l}\text { ISAC-CNR } \\
\text { of Rome }\end{array}$ & $\begin{array}{l}\text { Arpae Emilia } \\
\text { Romagna }\end{array}$ \\
\hline Location & & Monte Midia & Rome & $\begin{array}{l}\text { San Pietro } \\
\text { Capofiume }\end{array}$ \\
\hline Latitude & $(\operatorname{deg})$ & 42.057 & 41.840 & 44.6547 \\
\hline Longitude & (deg) & 13.177 & 12.647 & 11.6236 \\
\hline Height (a.s.1.) & $(\mathrm{m})$ & 1760 & 131 & 31 \\
\hline Doppler & & YES & YES & YES \\
\hline Dual polarization & & NO & YES & YES \\
\hline Range resolution & $(\mathrm{m})$ & 500 & 75 & 250 \\
\hline $\begin{array}{l}\text { Half-power beam } \\
\text { width }\end{array}$ & $(\operatorname{deg})$ & 1.6 & 1 & 0.9 \\
\hline Temporal resolution & (min) & 15 & 5 & 15 \\
\hline $\begin{array}{l}\text { Elevations angles } \\
\text { used in PPI scans }\end{array}$ & $(\operatorname{deg})$ & $0,1,2,3$ & $\begin{array}{l}0.6,1.6,2.6, \\
4.4,6.2,8.3, \\
11.0,14.6\end{array}$ & $\begin{array}{l}0.53,1.4,2.3, \\
3.2,4.1,5.0\end{array}$ \\
\hline Maximum range & $(\mathrm{km})$ & 120 or 240 & 120 & 125 \\
\hline
\end{tabular}

Reflectivities taken from three C-band Doppler radars operational during the IOP4 have been assimilated to improve IC. The radars have different technical characteristics and were operated with different scanning strategies and operational settings as shown in Table 1: each radar has a halfpower beam width of $1.6,1$, and $0.9^{\circ}$, respectively, for Monte Midia (MM), Polar55C (P55C), and San Pietro Capofiume (SPC), and a range resolution of 500, 75, and $250 \mathrm{~m}$.

MM and SPC radars are included in the Italian weather radar network, while $\mathrm{P} 55 \mathrm{C}$ radar is a research radar working on demand, which was operational during the IOPs of the HyMeX campaign (Roberto et al., 2016).

It is worth mentioning that radar data can be affected by numerous sources of errors, mainly due to ground clutter, attenuation due to propagation or beam blocking, anomalous propagation, and radio interference. This is the reason why a preliminary "cleaning" procedure is applied to the measured radar reflectivity from the three radars before the assimilation process, consisting of the following three steps:

- A first quality check of radar volumes to filter out radar pixels affected by ground clutter and anomalous propagation; furthermore, $Z$ was corrected for attenuation using a methodology based on the specific differential phase shift $\left(K_{\mathrm{dp}}\right)$ available for dual polarization radars (Vulpiani et al., 2015); moreover, reflectivity is not corrected for partial beam blocking: all the data that are affected by partial beam blocking and clutter have been filtered out.

- Volume reflectivity radar data are converted from their native polar coordinates (range, azimuth and altitude) into geographical Cartesian ones (latitude, longitude and altitude).

- The minimum assimilated reflectivity is set to $-20 \mathrm{dBZ}$.

Moreover, no observation thinning is performed because this procedure has not yet been developed into the 3-D-Var system for radar data. Instead, an iterative approach has been applied to extract more information from radar data during the assimilation procedure: this is the multiple outer loops technique explained in Sect. 4.

\subsection{3-D-Var data assimilation method}

Data assimilation (DA) is a technique employed in many fields of geosciences, perhaps most importantly in weather forecasting and hydrology. In this context it is the procedure by which observations are combined with the product (first guess or background forecast) of a NWP model and their corresponding error statistics, to produce a bettered estimate (the analysis) of the true state of the atmosphere (Skamarock et al., 2008). The variational DA method realizes this through the iterative minimization of a penalty function (Ide et al., 1997):

$$
\begin{aligned}
J(x) & =J^{b}(\boldsymbol{x})+J^{0}(\boldsymbol{x}) \\
& =\frac{1}{2}\left\{\left[\boldsymbol{y}^{0}-H(\boldsymbol{x})\right]^{T} \mathbf{R}^{-1}\left[\boldsymbol{y}^{0}-H(\boldsymbol{x})\right]\right. \\
& \left.+\left(\boldsymbol{x}-\boldsymbol{x}^{b}\right)^{T} \mathbf{B}^{-1}\left(\boldsymbol{x}-\boldsymbol{x}^{b}\right)\right\},
\end{aligned}
$$

where $\boldsymbol{x}^{b}$ is the first guess state vector, $\boldsymbol{y}^{0}$ is the assimilated observation vector, $H$ is the observation operator that links the model variables to the observation variables and $\boldsymbol{x}$ is the 
unknown analysis state vector to be found by minimizing $J(x)$. Finally, $\mathbf{B}$ and $\mathbf{R}$ are the background covariance error matrix and the observation covariance error matrix, respectively.

The minimization of the penalty function $J(x)$, displayed by Eq. (1), is the a posteriori maximum likelihood estimate of the true atmosphere state, given the two sources of a priori data that are $\boldsymbol{x}^{b}$ and $\boldsymbol{y}^{0}$ (Lorenc, 1986).

In this study the 3-D-Var system developed by Barker et al. $(2003,2004)$ is used for assimilating radar reflectivity and conventional observations SYNOP and TEMP. The penalty function minimization is performed in a preconditioned control variable space, where the preconditioned control variables are pseudo-relative humidity, stream function, unbalanced temperature, unbalanced potential velocity, and unbalanced surface pressure. Because of radar reflectivity assimilation is considered, the total water mixing ratio $q_{\mathrm{t}}$ is chosen as the moisture control variable. The following equation presents the observation operator used by the 3-D-Var to calculate reflectivity for the comparison with the observed one (Sun and Crook, 1997):

$Z=43.1+17.5 \log \left(\rho q_{\mathrm{r}}\right)$,

where $\rho$ and $q_{\mathrm{r}}$ are the air density in $\mathrm{kg} \mathrm{m}^{-3}$ and the rainwater mixing ratio in $\mathrm{g} \mathrm{kg}^{-1}$, respectively, while $Z$ is the co-polar radar reflectivity factor expressed in $\mathrm{dBZ}$. Since the total water mixing ratio $q_{\mathrm{t}}$ is used as the control variable, a warm rain process (Dudhia, 1989) is introduced into the WRF-3-D-Var system to allow for producing the increments of moist variables linked to the hydrometeors.

The performance of the DA system strongly depends on the quality of the $\mathbf{B}$ matrix in Eq. (1). In this study, a specific background error statistics is computed for both domains for the entire SOP1 duration using the National Meteorological Centre (NMC) method (Parrish and Derber, 1992). This technique estimates the initial state error using differences of couples of forecasts valid at the same time, but with one of them having a delayed start time. One of the advantage of this method is that it maintains information on the dynamic of the model itself, but it may not give the proper correlation structure on data-sparse observations. Commonly, for regional applications and to remove the diurnal cycle, a delay of $24 \mathrm{~h}$ between the forecasts $(T+24$ minus $T+12)$ is used; nevertheless, this delay can produce overestimated correlation length scales compared to those needed by a variational data assimilation technique, because of too dynamically evolved structures (Sadiki et al., 2000). Since 3-D-Var is applied to the Mediterranean area, $\mathbf{B}$ has to take into account the scale of the motions of this orographic and meteorologically complex area: the model grid resolution ranges between 12 and $3 \mathrm{~km}$, therefore the errors have to describe the physical phenomena relative to these scales.

\subsection{Evaluation}

The Point-Stat Tool of MET (Model Evaluation Tools) application (DTC, 2013), developed at the DTC (Developmental Testbed Centre, NCAR), has been used to objectively evaluate the $12 \mathrm{~h}$ accumulated precipitation produced by WRF on both domains. The interpolation method used to match the gridded model output to the point observation is the distance weighted mean in a $3 \times 3$ square of grid points. The observations used for the statistical evaluation were obtained from the DEWETRA platform of the Department of Civil Protection and the comparison has been performed over the central Italy target area using about 3000 rain gauges with a good coverage throughout the Italian territory. Moreover, for interpreting results from the verification analysis bootstrap, confidence intervals (CIs) have been used to analyse the uncertainty associated with the score's values. Bootstrapping is a non-parametric, computationally expensive, statistical technique (Efron and Tibshirani, 1993) for estimating parameters and uncertainty information, which allows us to make inferences from data without making strong distributional assumptions about the data or the statistic being calculated. Therefore, the idea was to estimate CIs to set some bounds (bootstrap upper and lower confidence limits) on the expected value of the verification score helping to assess whether differences between competing forecasts are significant.

\section{Design of the numerical experiments: discussion of the results}

The simulations on the coarser-resolution domain (D01) are run from 12:00 UTC on 13 September 2012 and integrated for the following $96 \mathrm{~h}$, whereas runs on the finestresolution domain (D02) started at 00:00 UTC on 14 September for a total of $48 \mathrm{~h}$ of integration. The previous coarserresolution WRF forecast at 00:00 UTC is used as the first guess in the 3-D-Var experiment, because 00:00 UTC has been selected as the "analysis time" of the assimilation procedure. After assimilation, the lateral and lower boundary conditions are updated for the high-resolution forecast. Finally, the new IC and BC are used for the model initialization (in a warm start regime) at 00:00 UTC. As already pointed out, a set of preliminary experiments are performed using different cumulus convective schemes to assess the best one to be used. The following experiments are performed without assimilation and using the convective scheme on the coarser-resolution domain only: KAIN-FRITSCH (KF_MYJ); GRELL3D (GRELL3D_MYJ); GRELL3D associated with the CUGD factor (GRELL3D_MYJ_CUGD). The best performance is obtained by the Grell3D scheme which is able to simulate the peak of precipitation cumulated in $24 \mathrm{~h}$ over Campo Imperatore, whereas KAIN-FRITSCH completely misses it (not shown here). The MET statisti- 
Table 2. List of experiments to test the impact of data assimilation.

\begin{tabular}{|c|c|c|c|c|}
\hline Experiment & Cumulus & Grid resolution & $\begin{array}{l}\text { Assimilation SYNOP } \\
+ \text { TEMP }\end{array}$ & Assimilation radar \\
\hline CTL & GRELL3D+CUGD & $12 \mathrm{KM} / 3 \mathrm{KM}$ & NO & NO \\
\hline $\mathrm{CON}$ & GRELL3D+CUGD & $12 \mathrm{KM} / 3 \mathrm{KM} / \mathrm{BOTH}$ & YES & NO \\
\hline CONMM & GRELL3D+CUGD & $12 \mathrm{KM} / 3 \mathrm{KM} / \mathrm{BOTH}$ & YES & MM \\
\hline CONMMPOL & GRELL3D+CUGD & $12 \mathrm{KM} / 3 \mathrm{KM} / \mathrm{BOTH}$ & YES & $\mathrm{MM}+\mathrm{POL}$ \\
\hline CONMMPOLSPC & GRELL3D+CUGD & $12 \mathrm{KM} / 3 \mathrm{KM} / \mathrm{BOTH}$ & YES & $\mathrm{MM}+\mathrm{POL}+\mathrm{SPC}$ \\
\hline CONMMPOLSPC3OL & GRELL3D+CUGD & $12 \mathrm{KM} / 3 \mathrm{KM} / \mathrm{BOTH}$ & YES & $\mathrm{MM}+\mathrm{POL}+\mathrm{SPC}$ with 3 outer loops \\
\hline
\end{tabular}

cal analysis supports the previous finding and the simulation with cugd_avedx activated shows a significant performance improvement in terms of uncertainty of the calculated scores than the other two simulations (not shown). Hereafter GRELL3D_MYJ_CUGD is referred to as the control experiment (CTL) performed without any data assimilation.

At this point analysis of a new set of simulations is performed allowing us to establish the best model configuration for the radar reflectivity assimilation. The DA experiments aim to investigate

1. the impact of the assimilation at low and high resolution by assimilating both conventional and non-conventional data at both resolutions;

2. the impact of the assimilation of different types of observations;

3. the impact of the different radars, which is investigated by performing experiments by assimilating conventional data and then adding radar one by one.

Therefore in Table 2, together with CTL simulation, the following DA experiments are summarized: (i) the assimilation of conventional data only (CON), (ii) the assimilation of reflectivity data from MM only is added (CONMM), (iii) the assimilation of $\mathrm{P} 55 \mathrm{C}$ radar reflectivity is added to the previous experiments (CONMMPOL), and (iv) the assimilation of the third radar reflectivity data is also added (CONMMPOLSPC). Finally, an experiment to assess the role of the outer loops is performed (CONMMPOLSPC3OL): to include nonlinearities into the observation operator and to evaluate the impact of reflectivity data entering for each cycle, the multiple outer loops strategy is applied (Hsiao et al., 2012). According to this approach, the nonlinear problem is solved iteratively as a progression of linear problems: the assimilation system is able to ingest more observations by running more than one analysis outer loop, allowing observations rejected in the previous loop to be entered into the subsequent one. Since radar data are nonlinearly related to the analysis control variables, the outer loops method is particularly helpful to extract more information from such data. For example, over a total amount of 518400 radar data (considering all the three radars), the fraction of radar observations assimilated into the $3 \mathrm{~km}$ domain is 32986 at the first outer iteration, 33001 at the second outer iteration, and 33027 at the last one.

In the following section the results will be presented and discussed following the rationale of the previously introduced experiments and analysing the uncertainty (confidence level of $95 \%$ ) in the realized scores (forecast accuracy (ACC), frequency bias (FBIAS), equitable threat score (ETS), and false alarm ratio (FAR)) for performance quantitative assessment.

\section{Impact of conventional measurements and radar reflectivity assimilation on rainfall forecast: low vs. high resolution}

In Fig. 6, a preliminary comparison among low-resolution (LR) simulations is shown. The control simulation (CTL) without data assimilation is shown in Fig. 6a; the other panels (Fig. 6b-f) show the experiments performed using the data assimilation.

The outputs of different experiments in Fig. 6 have been eyeballed and we found that CONMMPOLSPC_LR_12KM (black arrow in Fig. 6e) shows the most encouraging performance compared to the observed accumulated rainfall of Fig. 2: the rainfall maximum over Campo Imperatore is very well simulated; however a slight cell displacement at the border between Marche and Abruzzo regions is noticeable. The rain cumulated by the gauges in $24 \mathrm{~h}$ related to this cell is around $300 \mathrm{~mm}$ (Fig. 3c); in the simulations shown in Fig. 6b and $\mathrm{f}$ this cell is reproduced, although its position is shifted in another region. Furthermore, the precipitation pattern along the northern coasts of Abruzzo (black oval in Fig. 6e) is also quite well forecasted. At an objective comparison of the statistical indices (not shown here) with their relative upper and lower confidence limits for the $12 \mathrm{~h}$ accumulated precipitation and for two thresholds ( 1 and $40 \mathrm{~mm}$ for light and heavy rain regimes, respectively), we obtained likely good values for ACC and FAR for all the experiments and for heavy rain regimes, strengthened by a small uncertainty interval. On the other hand, for the lower threshold the values of FBIAS for all simulations, considering also the confidence intervals, are greater than one. One possible interpretation of the impact of 

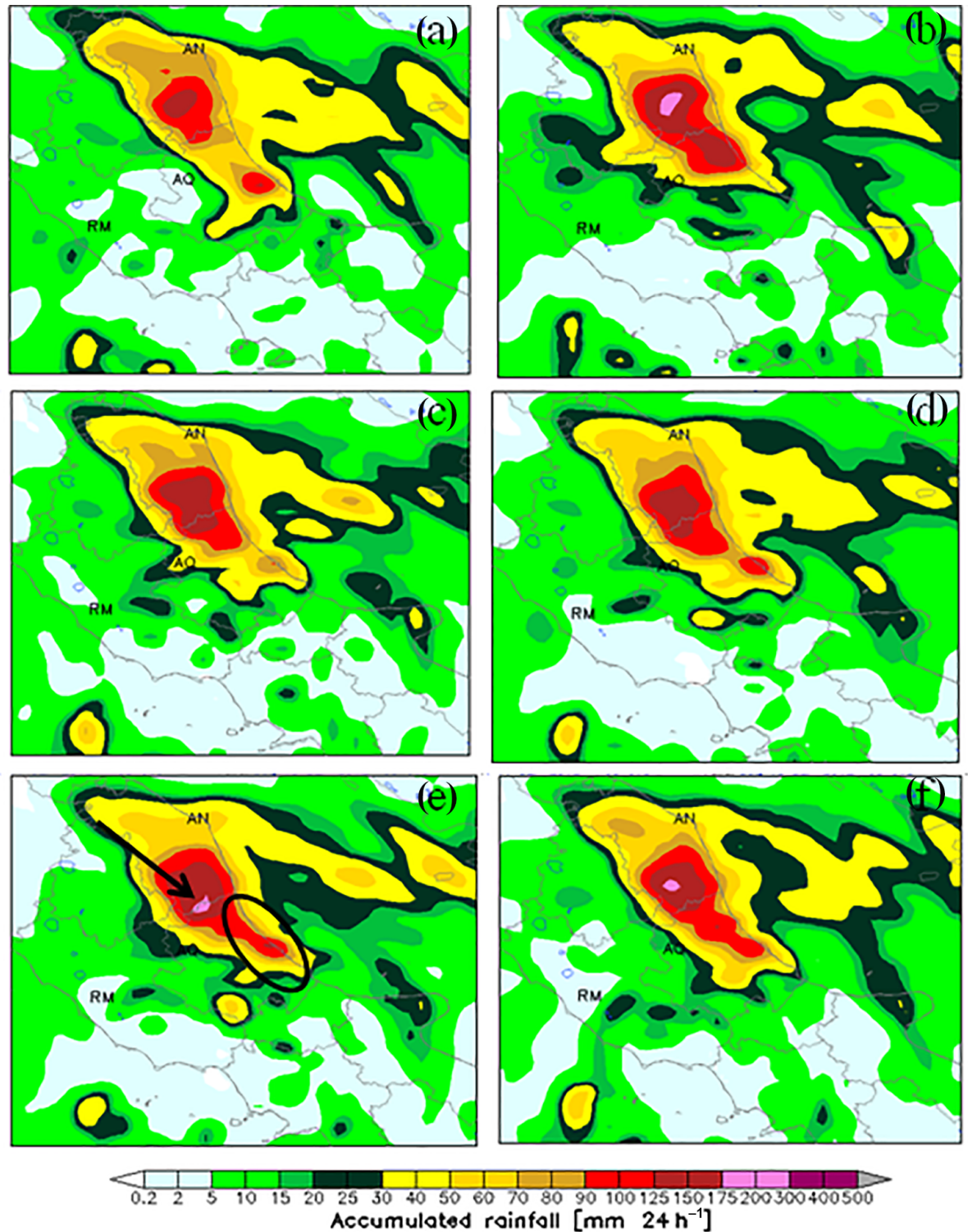

Figure 6. WRF D01 accumulated $24 \mathrm{~h}$ rainfall forecast over central Italy from 00:00 UTC on 14 September 2012: (a) WRF D01 CTL; (b) WRF D01 CON_LR_12KM; (c) WRF D01 CONMM_LR_12KM; (d) WRF D01 CONMMPOL_LR_12KM; (e) WRF D01 CONMMPOLSPC_LR_12KM; (f) WRF D01 CONMMPOLSPC3OL_LR_12KM.

the lower threshold is that with $95 \%$ confidence all the experiments are overestimating the frequency of precipitation around $1 \mathrm{~mm}(12 \mathrm{~h})^{-1}$.

Similarly to the above comparison, in Fig. 7 highresolution results (HR) obtained performing reflectivity assimilation on the $12 \mathrm{~km}$ domain (column 1), on the $3 \mathrm{~km}$ (column 2), and on the 12 and $3 \mathrm{~km}$ together (column 3 ) are presented; at the top of Fig. 7 the CTL experiment on D02 is shown. Figure 7 is organized as follows: viewing panels by line, on line 1 all the simulations with conventional data assimilation only $\left(\mathrm{CON}^{*}\right)$ are found; on line 2 all the experiments with the assimilation of the reflectivity data from $\mathrm{MM}$ radar added (CONMM*); on line 3 all the experiments with the assimilation of the reflectivity data from two Cband radars added (CONMMPOL*); on line 4 all the experiments with the assimilation of the reflectivity data from all three C-band radars added (CONMMPOLSPC*); on line 5 the simulations where the strategy of outer loops is adopted (CONMMPOLSPC3OL*). In order to quantify the uncertainty associated with these experiments, the bootstrap $95 \%$ confidence intervals for verification statistics ACC, FBIAS, ETS, FAR have been summarized over Tables 3-5 reporting the two thresholds of precipitation for light and heavy rain regimes: 1 and $40 \mathrm{~mm}(12 \mathrm{~h})^{-1}$, respectively.

In order to investigate the impact of the assimilation at different resolutions, we examine Fig. 7 by column and also 
CTL

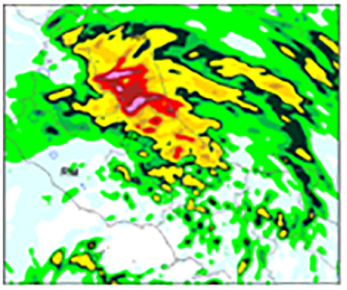

\section{Column 1}

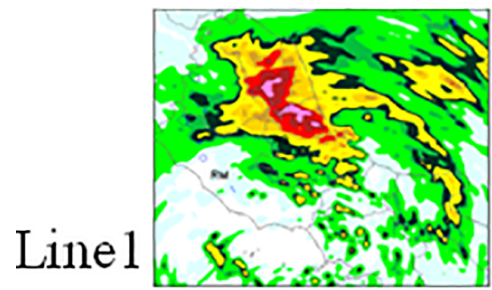

Column2
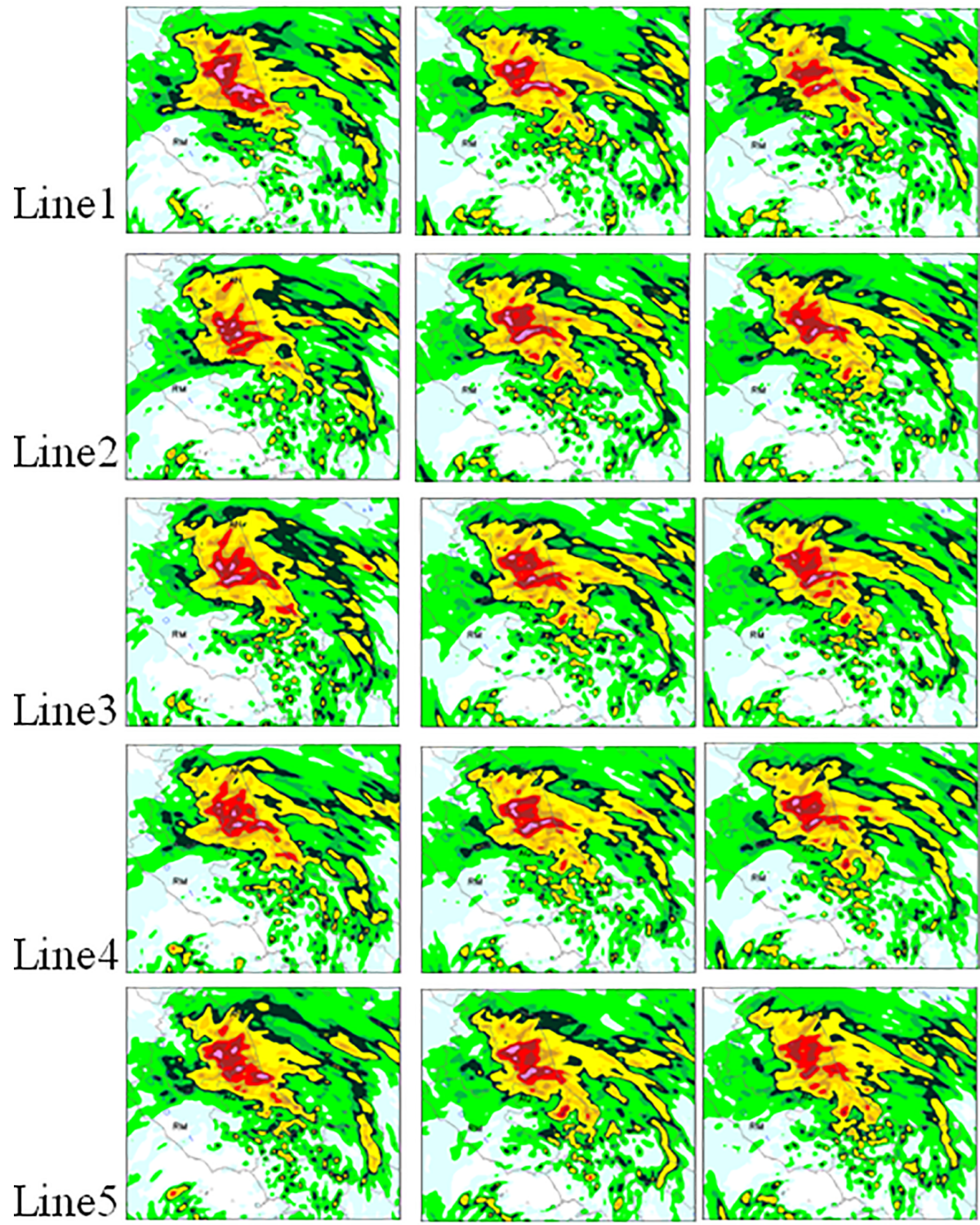

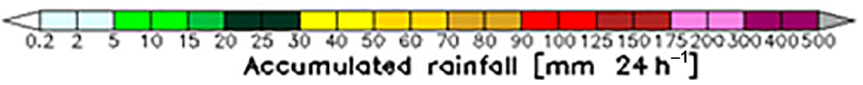

Figure 7. WRF D02 accumulated $24 \mathrm{~h}$ rainfall forecast over central Italy from 00:00 UTC on 14 September 2012: CTL simulation (top centre); on each column are simulations obtained performing reflectivity assimilation at different resolutions $\left(* 12 \mathrm{KM}, * 3 \mathrm{KM}, * 12 \mathrm{KM} \_3 \mathrm{KM}\right)$; on each line are simulations performed assimilating different kinds of data $\left(\mathrm{CON}^{*}, \mathrm{CONMM}^{*}, \mathrm{CONMMPOL}^{*}, \mathrm{CONMMPOLSPC} *, \mathrm{CON}^{-}\right.$ MMPOLSPC3OL*). 
Table 3. Bootstrap $95 \%$ confidence intervals for verification statistics forecast accuracy (ACC), frequency bias (FBIAS), equitable threat score (ETS), false alarm ratio (FAR), and referring to experiments in columns 2 and 3 of Fig. 7, respectively. They are considered as a function of thresholds $\left(1\right.$ and $\left.40 \mathrm{~mm}(12 \mathrm{~h})^{-1}\right)$. The experiments are CTL, CON_3KM and CON_12KM_3KM, CONMM_3KM and CONMM_12KM_3KM, CONMMPOL_3KM and CONMMPOL_12KM_3KM, CONMMPOLSPC_3KM and CONMMPOLSPC_12KM_3KM, CONMMPOLSPC3OL_3KM and CONMMPOLSPC3OL_12KM_3KM. The numbers in bold font represent the value between bootstrap upper and lower confidence limits.

\begin{tabular}{|c|c|c|c|c|c|c|c|c|}
\hline \multirow[t]{2}{*}{ Experiment } & \multicolumn{2}{|c|}{$\begin{array}{l}\text { ACC } \\
\text { thresholds } \\
\mathrm{mm}(12 \mathrm{~h})^{-1}\end{array}$} & \multicolumn{2}{|c|}{$\begin{array}{l}\text { FBIAS } \\
\text { thresholds } \\
\mathrm{mm}(12 \mathrm{~h})^{-1}\end{array}$} & \multicolumn{2}{|c|}{$\begin{array}{l}\text { ETS } \\
\text { thresholds } \\
\mathrm{mm}(12 \mathrm{~h})^{-1}\end{array}$} & \multicolumn{2}{|c|}{$\begin{array}{l}\text { FAR } \\
\text { thresholds } \\
\mathrm{mm}(12 \mathrm{~h})^{-1}\end{array}$} \\
\hline & 1 & 40 & 1 & 40 & 1 & 40 & 1 & 40 \\
\hline \multirow[t]{3}{*}{ CTL } & $(0.80)$ & $(0.96)$ & $(0.79)$ & $(0.14)$ & $(0.23)$ & $(0.04)$ & $(0.16)$ & $(0.001)$ \\
\hline & 0.83 & 0.98 & 0.94 & 0.47 & 0.33 & 0.10 & 0.21 & 0.007 \\
\hline & $(0.87)$ & $(0.99)$ & $(1.13)$ & $(1.61)$ & $(0.45)$ & $(0.16)$ & $(0.27)$ & $(0.015)$ \\
\hline \multirow[t]{3}{*}{ CON_3KM } & $(0.78)$ & $(0.96)$ & $(0.65)$ & $(0.08)$ & $(0.14)$ & $(0.03)$ & $(0.17)$ & $(0.001)$ \\
\hline & 0.82 & 0.98 & 0.80 & 0.18 & 0.24 & 0.06 & 0.22 & 0.004 \\
\hline & $(0.85)$ & $(0.99)$ & $(0.98)$ & $(0.42)$ & $(0.35)$ & $(0.12)$ & $(0.28)$ & $(0.009)$ \\
\hline \multirow[t]{3}{*}{ CON_12KM_3KM } & $(0.77)$ & $(0.96)$ & $(0.68)$ & $(0.02)$ & $(0.11)$ & $(0.01)$ & $(0.21)$ & $(0)$ \\
\hline & 0.81 & 0.98 & 0.84 & 0.10 & 0.20 & 0.04 & 0.27 & 0.001 \\
\hline & $(0.84)$ & $(0.99)$ & $(1.03)$ & $(0.34)$ & $(0.30)$ & $(0.007)$ & $(0.33)$ & $(0.004)$ \\
\hline \multirow[t]{3}{*}{ CONMM_3KM } & $(0.78)$ & $(0.97)$ & $(0.79)$ & $(0.14)$ & $(0.17)$ & $(0.05)$ & $(0.18)$ & $(0.001)$ \\
\hline & 0.82 & 0.98 & 0.96 & 0.31 & 0.26 & 0.13 & 0.24 & 0.005 \\
\hline & $(0.86)$ & $(0.99)$ & $(1.17)$ & $(0.68)$ & $(0.37)$ & $(0.26)$ & $(0.29)$ & $(0.11)$ \\
\hline \multirow[t]{3}{*}{ CONMM_12KM_3KM } & $(0.79)$ & $(0.96)$ & $(0.79)$ & (0.09) & $(0.18)$ & $(0.03)$ & $(0.17)$ & $(0.001)$ \\
\hline & 0.83 & 0.98 & 0.96 & 0.31 & 0.28 & 0.07 & 0.23 & 0.006 \\
\hline & $(0.86)$ & $(0.99)$ & (1.18) & $(1.02)$ & $(0.40)$ & $(0.13)$ & $(0.29)$ & $(0.013)$ \\
\hline \multirow{3}{*}{ CONMMPOL_3KM } & $(0.77)$ & $(0.96)$ & $(0.76)$ & $(0.12)$ & $(0.13)$ & $(0.03)$ & $(0.18)$ & $(0.001)$ \\
\hline & 0.81 & 0.98 & 0.94 & 0.28 & 0.23 & 0.09 & 0.24 & 0.006 \\
\hline & $(0.85)$ & $(0.99)$ & $(1.16)$ & $(0.65)$ & $(0.33)$ & $(0.14)$ & $(0.30)$ & $(0.11)$ \\
\hline \multirow[t]{3}{*}{ CONMMPOL_12KM_3KM } & $(0.77)$ & $(0.96)$ & $(0.79)$ & $(0.11)$ & $(0.14)$ & $(0.03)$ & $(0.19)$ & $(0.001)$ \\
\hline & 0.81 & 0.98 & 0.96 & 0.26 & 0.23 & 0.08 & 0.25 & 0.006 \\
\hline & $(0.85)$ & $(0.99)$ & $(1.19)$ & $(0.65)$ & $(0.33)$ & $(0.14)$ & $(0.31)$ & $(0.011)$ \\
\hline \multirow[t]{3}{*}{ CONMMPOLSPC_3KM } & $(0.78)$ & $(0.96)$ & $(0.85)$ & $(0.10)$ & $(0.18)$ & $(0.03)$ & $(0.19)$ & $(0.001)$ \\
\hline & 0.82 & 0.98 & 1.03 & 0.27 & 0.28 & 0.07 & 0.24 & 0.005 \\
\hline & $(0.86)$ & $(0.99)$ & $(1.25)$ & $(0.83)$ & $(0.39)$ & $(0.13)$ & $(0.31)$ & $(0.012)$ \\
\hline \multirow[t]{3}{*}{ CONMMPOLSPC_12KM_3KM } & $(0.77)$ & $(0.97)$ & $(0.87)$ & $(0.09)$ & $(0.16)$ & $(0.04)$ & $(0.22)$ & (0) \\
\hline & 0.81 & 0.98 & 1.04 & 0.25 & 0.26 & 0.08 & 0.28 & 0.004 \\
\hline & $(0.85)$ & $(0.99)$ & $(1.28)$ & $(0.70)$ & $(0.37)$ & $(0.14)$ & $(0.34)$ & $(0.009)$ \\
\hline \multirow[t]{3}{*}{ CONMMPOLSPC3OL_3KM } & $(0.79)$ & $(0.97)$ & $(0.81)$ & $(0.10)$ & $(0.17)$ & $(0.05)$ & $(0.21)$ & $(0.000)$ \\
\hline & 0.83 & 0.98 & 0.96 & 0.24 & 0.27 & 0.12 & 0.27 & 0.003 \\
\hline & $(0.86)$ & $(0.99)$ & $(1.17)$ & $(0.64)$ & $(0.39)$ & $(0.19)$ & $(0.33)$ & $(0.007)$ \\
\hline \multirow[t]{3}{*}{ CONMMPOLSPC3OL_12KM_3KM } & $(0.79)$ & $(0.97)$ & $(0.82)$ & $(0.08)$ & $(0.19)$ & $(0.05)$ & $(0.19)$ & (0) \\
\hline & 0.83 & 0.98 & 0.98 & 0.15 & 0.30 & 0.11 & 0.25 & 0.002 \\
\hline & $(0.86)$ & (0.99) & (1.18) & $(0.24)$ & $(0.41)$ & $(0.18)$ & $(0.31)$ & $(0.003)$ \\
\hline
\end{tabular}

compare with the available observations (Fig. 2) using the statistical analysis:

- Column 1 (12KM): CTL produces an overestimation of the rainfall that is not corrected by the assimilation of conventional data, but assimilating the reflectivity from the three radars (column 1 line 4) and also introducing the three outer loops (column 1 line 5) the main cells are better reproduced. MET indices (not shown here) suggest that CTL and CON_HR_12KM have the largest difference between the CIs bounds for higher thresholds of FBIAS: this result suggests that the remaining simulations, with smallest difference in CI limits and 
with both bounds lower than 1 , surely underestimate the frequency of heavy precipitating events. Another aspect to point out is that some indices for all simulations are quite close to each other and within the CIs, so it is not possible to discern which is the best experiment over all.

- Column 2 (3KM): a partial correction of the rainfall overestimation compared to column 1 is observed especially if reflectivity from all the radars are assimilated together with conventional data and the outer loops strategy is applied (column 2 line 5); the statistical indices in Table 3 show the most competitive experiment among the assimilated ones to be the $\mathrm{CON}$ MMPOLSPC3OL_3KM for lower threshold of rain for ACC (0.83) and FBIAS (0.96). On the other hand CONMM_3KM is the most promising simulation for heavy rain threshold for the indices FBIAS (0.31) and ETS (0.13).

- Column 3 (12KM_3KM): rainfall overestimation was partially corrected compared to columns 1 and 2 by all experiments; the MET statistics in Table 3 shows that CTL and CONMMPOLSPC3OL_12KM_3KM are the experiments with encouraging values and small uncertainty for ACC and ETS especially for light rain regimes, although there is a quite broad spread in FBIAS for CTL experiment (score 0.47 , with a lower and upper CI limit of respectively 0.14 and 1.61) if we consider higher thresholds.

The frequency of rainfall underestimation for higher thresholds found in the mother domain when radar reflectivity data are assimilated in D01 only has been reduced by switching to a higher-resolution domain; moreover, the overestimation of the frequency for lower thresholds has been corrected because the FBIAS, previously systematically above 1 is found to be approximately 1 (indices not shown). Furthermore, general improvements (especially for FBIAS and ETS) come out for heavy rain regimes when radar reflectivity assimilation has been performed on the highest resolution domain, whereas the ingestion of conventional observations produces the worst results for FBIAS and ETS since a smaller number of them were assimilated into the finestresolution domain (for instance one sounding out of five total) than that the coarser one. Data assimilation, operated on both the 12 and $3 \mathrm{~km}$ domains, shows similar performances to the experiments where assimilation is performed only on D01, but a worse response for higher thresholds (Table 3) than the ones where assimilation is carried out on D02.

In order to examine the impact of the assimilation of different data and radars, we can now analyse the experiments shown in Fig. 7 line by line. The results are compared with the observations of Fig. 2. The following considerations are worth discussing:

- Line $1(\mathrm{CON})$ : a strong reduction of the rainfall is found with respect to CTL if conventional data are assimilated, but the rainfall pattern remains unchanged. Statistical indices of CON experiment (Table 4) do not improve the performances of CTL (despite a reduction in some cases of the spread between the CI limits for higher thresholds of the FBIAS). Some indices values suggest a slightly better performance when the conventional observations are assimilated only on the bigger domain and for higher thresholds (FBIAS 0.49), together with an improvement of FAR index for heavy rain regime (FAR 0.001).

- Line 2 (CONMM): a further reduction in the precipitation overestimation is found as well as some variations in the pattern of the rainfall; the scores in Table 4, together with their bootstrap upper and lower limits, show that MM radar reflectivity and conventional observations assimilation, improves the model performance above all for lower thresholds with respect to the experiments where only SYNOP and TEMP were incorporated. It also applies for some of the scores at higher thresholds (for example for ETS).

- Line 3 (CONMMPOL): a quite strong improvement in the rainfall amount is found for all simulations. However, from the statistics of Table 4, we found a general worsening of the results both for light and heavy rain regimes when POL is added (especially for FBIAS and ETS, in some cases also for ACC and FAR at lower thresholds).

- Line 4 (CONMMPOLSPC): a clear correction of the rainfall pattern is found; the overestimation produced by the simulation where the reflectivity from all the radars are assimilated on the $3 \mathrm{~km}$ domain has been corrected by the experiment in which the reflectivity is assimilated both on D01 and D02; the uncertainty in the realized scores of Table 4 suggests that the addition of SPC radar improves the results; furthermore, they are not better than those where only MM is ingested.

- Line 5 (CONMMPOLSPC3OL): the outer loops experiment confirms the strong overestimation reduction by *12KM_3KM; from Table 5 it seems that the introduction of $3 \mathrm{OL}$ improves the indices estimate and bounds above all when the $12 \mathrm{~km}$ domain is considered (see FBIAS and ETS for both rain regimes and FAR for lower thresholds).

In summary, simulation results show that assimilation of conventional data shows better performance on the lowest resolution domain because more observations were used in the coarser domain, whereas when the assimilation is performed on the highest-resolution domain only few SYNOP and even less TEMP fell down in the $3 \mathrm{~km}$ domain at the analysis time of the assimilation procedure. The impact of conventional observations are expected to be lower than those of non-conventional ones, because most of them have already been used by ECMWF to produce their analysis and 
Table 4. Bootstrap $95 \%$ confidence intervals for verification statistics forecast accuracy (ACC), frequency bias (FBIAS), equitable threat score (ETS), false alarm ratio (FAR), and referring to experiments in lines 1-4 of Fig. 7. They are considered as a function of thresholds $\left(1\right.$ and $\left.40 \mathrm{~mm}(12 \mathrm{~h})^{-1}\right)$. The experiments are CTL, CON_3KM/CONMM_3KM/CONMMPOL_3KM/CONMMPOLSPC_3KM, CON_HR_12KM/CONMM_HR_12KM/CONMMPOL_HR_12KM/CONMMPOLSPC_12KM,

CON_12KM_3KM/CONMM_12KM_3KM/CONMMPOL_12KM_3KM/CONMMPOLSPC_12KM_3KM. The numbers in bold font represent the value between bootstrap upper and lower confidence limits.

\begin{tabular}{|c|c|c|c|c|c|c|c|c|}
\hline \multirow[t]{2}{*}{ Experiment } & \multicolumn{2}{|c|}{$\begin{array}{l}\text { ACC } \\
\text { thresholds } \\
\mathrm{mm}(12 \mathrm{~h})^{-1}\end{array}$} & \multicolumn{2}{|c|}{$\begin{array}{l}\text { FBIAS } \\
\text { thresholds } \\
\mathrm{mm}(12 \mathrm{~h})^{-1}\end{array}$} & \multicolumn{2}{|c|}{$\begin{array}{l}\text { ETS } \\
\text { thresholds } \\
\mathrm{mm}(12 \mathrm{~h})^{-1}\end{array}$} & \multicolumn{2}{|c|}{$\begin{array}{l}\text { FAR } \\
\text { thresholds } \\
\mathrm{mm}(12 \mathrm{~h})^{-1}\end{array}$} \\
\hline & 1 & 40 & 1 & 40 & 1 & 40 & 1 & 40 \\
\hline CTL & $\begin{array}{l}(0.80) \\
\mathbf{0 . 8 3} \\
(0.87)\end{array}$ & $\begin{array}{l}(0.96) \\
\mathbf{0 . 9 8} \\
(0.99)\end{array}$ & $\begin{array}{l}(0.79) \\
\mathbf{0 . 9 4} \\
(1.13)\end{array}$ & $\begin{array}{l}(0.14) \\
\mathbf{0 . 4 7} \\
(1.61)\end{array}$ & $\begin{array}{l}(0.23) \\
\mathbf{0 . 3 3} \\
(0.45)\end{array}$ & $\begin{array}{l}(0.04) \\
\mathbf{0 . 1 0} \\
(0.16)\end{array}$ & $\begin{array}{l}(0.16) \\
\mathbf{0 . 2 1} \\
(0.27)\end{array}$ & $\begin{array}{l}(0.001) \\
\mathbf{0 . 0 0 7} \\
(0.014)\end{array}$ \\
\hline CON_3KM & $\begin{array}{l}(0.78) \\
\mathbf{0 . 8 2} \\
(0.85)\end{array}$ & $\begin{array}{l}(0.96) \\
\mathbf{0 . 9 8} \\
(0.99)\end{array}$ & $\begin{array}{l}(0.65) \\
\mathbf{0 . 8 0} \\
(0.98)\end{array}$ & $\begin{array}{l}(0.08) \\
\mathbf{0 . 1 8} \\
(0.42)\end{array}$ & $\begin{array}{l}(0.14) \\
\mathbf{0 . 2 4} \\
(0.35)\end{array}$ & $\begin{array}{l}(0.03) \\
\mathbf{0 . 0 6} \\
(0.12)\end{array}$ & $\begin{array}{l}(0.17) \\
\mathbf{0 . 2 2} \\
(0.28)\end{array}$ & $\begin{array}{l}(0.001) \\
\mathbf{0 . 0 0 4} \\
(0.009)\end{array}$ \\
\hline CONMM_3KM & $\begin{array}{l}(0.78) \\
\mathbf{0 . 8 2} \\
(0.86)\end{array}$ & $\begin{array}{l}(0.97) \\
\mathbf{0 . 9 8} \\
(0.99)\end{array}$ & $\begin{array}{l}(0.79) \\
\mathbf{0 . 9 6} \\
(1.17)\end{array}$ & $\begin{array}{l}(0.14) \\
\mathbf{0 . 3 1} \\
(0.68)\end{array}$ & $\begin{array}{l}(0.17) \\
\mathbf{0 . 2 6} \\
(0.37)\end{array}$ & $\begin{array}{l}(0.05) \\
\mathbf{0 . 1 3} \\
(0.26)\end{array}$ & $\begin{array}{l}(0.18) \\
\mathbf{0 . 2 4} \\
(0.29)\end{array}$ & $\begin{array}{l}(0.001) \\
\mathbf{0 . 0 0 5} \\
(0.011)\end{array}$ \\
\hline CONMMPOL_3KM & $\begin{array}{l}(0.77) \\
\mathbf{0 . 8 1} \\
(0.85)\end{array}$ & $\begin{array}{l}(0.96) \\
\mathbf{0 . 9 8} \\
(0.99)\end{array}$ & $\begin{array}{l}(0.76) \\
\mathbf{0 . 9 4} \\
(1.16)\end{array}$ & $\begin{array}{l}(0.12) \\
\mathbf{0 . 2 8} \\
(0.65)\end{array}$ & $\begin{array}{l}(0.13) \\
\mathbf{0 . 2 3} \\
(0.33)\end{array}$ & $\begin{array}{l}(0.03) \\
\mathbf{0 . 0 9} \\
(0.14)\end{array}$ & $\begin{array}{l}(0.18) \\
\mathbf{0 . 2 4} \\
(0.30)\end{array}$ & $\begin{array}{l}(0.001) \\
\mathbf{0 . 0 0 6} \\
(0.011)\end{array}$ \\
\hline CONMMPOLSPC_3KM & $\begin{array}{l}(0.78) \\
\mathbf{0 . 8 2} \\
(0.86)\end{array}$ & $\begin{array}{l}(0.96) \\
\mathbf{0 . 9 8} \\
(0.99)\end{array}$ & $\begin{array}{l}(0.85) \\
\mathbf{1 . 0 3} \\
(1.25)\end{array}$ & $\begin{array}{l}(0.10) \\
\mathbf{0 . 2 7} \\
(0.83)\end{array}$ & $\begin{array}{l}(0.18) \\
\mathbf{0 . 2 8} \\
(0.39)\end{array}$ & $\begin{array}{l}(0.03) \\
\mathbf{0 . 0 7} \\
(0.13)\end{array}$ & $\begin{array}{l}(0.19) \\
\mathbf{0 . 2 5} \\
(0.31)\end{array}$ & $\begin{array}{l}(0.001) \\
\mathbf{0 . 0 0 5} \\
(0.012)\end{array}$ \\
\hline CON_HR_12KM & $\begin{array}{l}(0.77) \\
\mathbf{0 . 8 1} \\
(0.85)\end{array}$ & $\begin{array}{l}(0.96) \\
\mathbf{0 . 9 7} \\
(0.99)\end{array}$ & $\begin{array}{l}(0.75) \\
0.91 \\
(1.11)\end{array}$ & $\begin{array}{l}(0.21) \\
\mathbf{0 . 4 9} \\
(1.61)\end{array}$ & $\begin{array}{l}(0.15) \\
\mathbf{0 . 2 5} \\
(0.36)\end{array}$ & $\begin{array}{l}(0.03) \\
\mathbf{0 . 0 7} \\
(0.13)\end{array}$ & $\begin{array}{l}(0.20) \\
\mathbf{0 . 2 6} \\
(0.31)\end{array}$ & $\begin{array}{l}(0.005) \\
\mathbf{0 . 0 0 1 1} \\
(0.19)\end{array}$ \\
\hline CONMM_HR_12KM & $\begin{array}{l}(07.8) \\
\mathbf{0 . 8 2} \\
(0.86)\end{array}$ & $\begin{array}{l}(0.97) \\
\mathbf{0 . 9 8} \\
(0.99)\end{array}$ & $\begin{array}{l}(0.79) \\
\mathbf{0 . 9 5} \\
(1.16)\end{array}$ & $\begin{array}{l}(0.15) \\
\mathbf{0 . 2 9} \\
(0.64)\end{array}$ & $\begin{array}{l}(0.18) \\
\mathbf{0 . 2 8} \\
(0.39)\end{array}$ & $\begin{array}{l}(0.07) \\
\mathbf{0 . 1 4} \\
(0.21)\end{array}$ & $\begin{array}{l}(0.19) \\
\mathbf{0 . 2 4} \\
(0.31)\end{array}$ & $\begin{array}{l}(0) \\
\mathbf{0 . 0 0 4} \\
(0.008)\end{array}$ \\
\hline CONMMPOL_HR_12KM & $\begin{array}{l}(0.76) \\
\mathbf{0 . 8 0} \\
(0.84)\end{array}$ & $\begin{array}{l}(0.97) \\
\mathbf{0 . 9 8} \\
(0.99)\end{array}$ & $\begin{array}{l}(0.66) \\
\mathbf{0 . 8 2} \\
(1.01)\end{array}$ & $\begin{array}{l}(0.07) \\
\mathbf{0 . 1 4} \\
(0.25)\end{array}$ & $\begin{array}{l}(0.10) \\
\mathbf{0 . 2 0} \\
(0.30)\end{array}$ & $\begin{array}{l}(0.03) \\
\mathbf{0 . 0 0 6} \\
(0.11)\end{array}$ & $\begin{array}{l}(0.20) \\
\mathbf{0 . 2 5} \\
(0.31)\end{array}$ & $\begin{array}{l}(0.001) \\
\mathbf{0 . 0 0 3} \\
(0.006)\end{array}$ \\
\hline CONMMPOLSPC_HR_12KM & $\begin{array}{l}(0.78) \\
\mathbf{0 . 8 2} \\
(0.86)\end{array}$ & $\begin{array}{l}(0.96) \\
\mathbf{0 . 9 8} \\
(0.99)\end{array}$ & $\begin{array}{l}(0.71) \\
\mathbf{0 . 8 6} \\
(1.05)\end{array}$ & $\begin{array}{l}(0.08) \\
\mathbf{0 . 2 2} \\
(0.59)\end{array}$ & $\begin{array}{l}(0.17) \\
\mathbf{0 . 2 8} \\
(0.39)\end{array}$ & $\begin{array}{l}(0.02) \\
\mathbf{0 . 0 6} \\
(0.12)\end{array}$ & $\begin{array}{l}(0.16) \\
\mathbf{0 . 2 1} \\
(0.27)\end{array}$ & $\begin{array}{l}(0.001) \\
\mathbf{0 . 0 0 5} \\
(0.11)\end{array}$ \\
\hline CON_12KM_3KM & $\begin{array}{l}(0.77) \\
\mathbf{0 . 8 1} \\
(0.84)\end{array}$ & $\begin{array}{l}(0.96) \\
\mathbf{0 . 9 8} \\
(0.99)\end{array}$ & $\begin{array}{l}(0.68) \\
\mathbf{0 . 8 4} \\
(1.03)\end{array}$ & $\begin{array}{l}(0.02) \\
\mathbf{0 . 1 0} \\
(0.34)\end{array}$ & $\begin{array}{l}(0.11) \\
\mathbf{0 . 2 0} \\
(0.30)\end{array}$ & $\begin{array}{l}(0.01) \\
\mathbf{0 . 0 4} \\
(0.07)\end{array}$ & $\begin{array}{l}(0.21) \\
\mathbf{0 . 2 7} \\
(0.33)\end{array}$ & $\begin{array}{l}(0) \\
\mathbf{0 . 0 0 1} \\
(0.004)\end{array}$ \\
\hline CONMM_12KM_3KM & $\begin{array}{l}(0.79) \\
\mathbf{0 . 8 3} \\
(0.86)\end{array}$ & $\begin{array}{l}(0.96) \\
\mathbf{0 . 9 8} \\
(0.99)\end{array}$ & $\begin{array}{l}(0.79) \\
\mathbf{0 . 9 6} \\
(1.18)\end{array}$ & $\begin{array}{l}(0.09) \\
\mathbf{0 . 3 1} \\
(1.01)\end{array}$ & $\begin{array}{l}(0.18) \\
\mathbf{0 . 2 8} \\
(0.40)\end{array}$ & $\begin{array}{l}(0.03) \\
\mathbf{0 . 0 7} \\
(0.13)\end{array}$ & $\begin{array}{l}(0.17) \\
\mathbf{0 . 2 3} \\
(0.29)\end{array}$ & $\begin{array}{l}(0.001) \\
\mathbf{0 . 0 0 6} \\
(0.013)\end{array}$ \\
\hline CONMMPOL_12KM_3KM & $\begin{array}{l}(0.77) \\
\mathbf{0 . 8 1} \\
(0.85)\end{array}$ & $\begin{array}{l}(0.96) \\
\mathbf{0 . 9 8} \\
(0.99)\end{array}$ & $\begin{array}{l}(0.79) \\
\mathbf{0 . 9 6} \\
(1.19)\end{array}$ & $\begin{array}{l}(0.11) \\
\mathbf{0 . 2 6} \\
(0.65)\end{array}$ & $\begin{array}{l}(0.14) \\
\mathbf{0 . 2 3} \\
(0.33)\end{array}$ & $\begin{array}{l}(0.03) \\
\mathbf{0 . 0 8} \\
(0.13)\end{array}$ & $\begin{array}{l}(0.19) \\
\mathbf{0 . 2 5} \\
(0.31)\end{array}$ & $\begin{array}{l}(0.01) \\
\mathbf{0 . 0 0 5} \\
(0.011)\end{array}$ \\
\hline CONMMPOLSPC_12KM_3KM & $\begin{array}{l}(0.77) \\
\mathbf{0 . 8 1} \\
(0.85)\end{array}$ & $\begin{array}{l}(0.96) \\
\mathbf{0 . 9 8} \\
(0.99)\end{array}$ & $\begin{array}{l}(0.87) \\
\mathbf{1 . 0 4} \\
(1.28)\end{array}$ & $\begin{array}{l}(0.09) \\
\mathbf{0 . 2 5} \\
(0.70)\end{array}$ & $\begin{array}{l}(0.16) \\
\mathbf{0 . 2 6} \\
(0.36)\end{array}$ & $\begin{array}{l}(0.04) \\
\mathbf{0 . 0 8} \\
(0.14)\end{array}$ & $\begin{array}{l}(0.22) \\
\mathbf{0 . 2 8} \\
(0.34)\end{array}$ & $\begin{array}{l}(0) \\
\mathbf{0 . 0 0 4} \\
(0.009)\end{array}$ \\
\hline
\end{tabular}


Table 5. Bootstrap $95 \%$ confidence intervals for verification statistics forecast accuracy (ACC), frequency bias (FBIAS), equitable threat score (ETS), false alarm ratio (FAR), and referring to experiments in line 5 of Fig. 7. They are considered as a function of thresholds (1 and $\left.40 \mathrm{~mm}(12 \mathrm{~h})^{-1}\right)$. The experiments are CTL, CONMMPOLSPC3OL_3KM, CONMMPOLSPC3OL_HR_12KM,

CONMMPOLSPC3OL_12KM_3KM. The numbers in bold font represent the value between bootstrap upper and lower confidence limits.

\begin{tabular}{llllllllll}
\hline Experiment & \multicolumn{2}{l}{$\begin{array}{l}\text { ACC } \\
\text { thresholds }\end{array}$} & \multicolumn{2}{l}{$\begin{array}{l}\text { FBIAS } \\
\text { thresholds }\end{array}$} & \multicolumn{2}{l}{$\begin{array}{l}\text { ETS } \\
\text { thresholds }\end{array}$} & \multicolumn{2}{l}{$\begin{array}{l}\text { FAR } \\
\text { thresholds }\end{array}$} \\
& mm $(12 \mathrm{~h})^{-1}$ & \multicolumn{2}{l}{$\mathrm{mm}(12 \mathrm{~h})^{-1}$} & \multicolumn{2}{l}{$\begin{array}{l}\mathrm{mm}(12 \mathrm{~h})^{-1} \\
\mathrm{~mm}(12 \mathrm{~h})^{-1}\end{array}$} \\
& 1 & 40 & 1 & 40 & 1 & 40 & 1 & 40 \\
\hline CTL & $(0.79)$ & $(0.96)$ & $(0.79)$ & $(0.14)$ & $(0.23)$ & $(0.04)$ & $(0.16)$ & $(0.001)$ \\
& $\mathbf{0 . 8 3}$ & $\mathbf{0 . 9 8}$ & $\mathbf{0 . 9 4}$ & $\mathbf{0 . 4 7}$ & $\mathbf{0 . 3 3}$ & $\mathbf{0 . 1 0}$ & $\mathbf{0 . 2 1}$ & $\mathbf{0 . 0 0 7}$ \\
& $(0.87)$ & $(0.99)$ & $(1.13)$ & $(1.61)$ & $(0.44)$ & $(0.16)$ & $(0.27)$ & $(0.015)$ \\
CONMMPOLSPC3OL_3KM & $(0.79)$ & $(0.97)$ & $(0.81)$ & $(0.10)$ & $(0.17)$ & $(0.05)$ & $(0.21)$ & $(0)$ \\
& $\mathbf{0 . 8 3}$ & $\mathbf{0 . 9 8}$ & $\mathbf{0 . 9 6}$ & $\mathbf{0 . 2 4}$ & $\mathbf{0 . 2 7}$ & $\mathbf{0 . 1 2}$ & $\mathbf{0 . 2 7}$ & $\mathbf{0 . 0 0 3}$ \\
& $(0.86)$ & $(0.99)$ & $(1.17)$ & $(0.64)$ & $(0.39)$ & $(0.19)$ & $(0.33)$ & $(0.007)$ \\
CONMMPOLSPC3OL_HR_12KM & $(0.78)$ & $(0.96)$ & $(0.77)$ & $(0.13)$ & $(0.20)$ & $(0.004)$ & $(0.14)$ & $(0.002)$ \\
& $\mathbf{0 . 8 2}$ & $\mathbf{0 . 9 8}$ & $\mathbf{0 . 9 3}$ & $\mathbf{0 . 3 1}$ & $\mathbf{0 . 3 0}$ & $\mathbf{0 . 1 0}$ & $\mathbf{0 . 2 0}$ & $\mathbf{0 . 0 0 6}$ \\
CONMMPOLSPC3OL_12KM_3KM & $(0.86)$ & $(0.99)$ & $(1.13)$ & $(0.86)$ & $(0.41)$ & $(0.17)$ & $(0.26)$ & $(0.012)$ \\
& $(0.79)$ & $(0.97)$ & $(0.82)$ & $(0.08)$ & $(0.19)$ & $(0.04)$ & $(0.19)$ & $(0)$ \\
& $\mathbf{0 . 8 3}$ & $\mathbf{0 . 9 8}$ & $\mathbf{0 . 9 8}$ & $\mathbf{0 . 1 5}$ & $\mathbf{0 . 3 0}$ & $\mathbf{0 . 1 1}$ & $\mathbf{0 . 2 5}$ & $\mathbf{0 . 0 0 2}$ \\
& $(0.86)$ & $(0.99)$ & $(1.18)$ & $(0.24)$ & $(0.41)$ & $(0.18)$ & $(0.31)$ & $(0.003)$ \\
\hline
\end{tabular}

they are here used as first guess, even if at lower resolution $\left(0.25^{\circ}\right)$. Therefore, they result in being correlated with the background and the improvements of those experiments where they are assimilated are expected to be low.

With regard to the assimilation of reflectivity radar data, it should be noted that P55C radar observations of the event considered is shielded at the lowest elevation angles by the Apennines range and provides a limited contribution to reflectivity data that are assimilated. Also, the outer loops strategy could have an important role in the assimilation procedure, but this needs further investigation (for example, additional work needs to be dedicated to testing the different tuning factors for both observation and background during each outer loop) because a general rainfall underestimation for higher thresholds is found.

The results of this section confirm that when there is a correlation between the observations and the first guess used, the results of the data assimilation are poor, especially if no "special" observation is available on a wide area. The assimilation of a large amount of surface data together with the radiosonde ones decreases the quality of the final analysis produced. It probably depends on the different density of the surface and the three-dimensional data of radiosondes, as assessed by Liu and Rabier (2002), the former being much larger than the latter.

\section{Conclusions}

In this paper the effects of multiple radar reflectivity data assimilation on a heavy precipitation event occurred during the SOP1 of the HyMeX campaign have been evaluated: the aim is to build a regionally tuned numerical prediction model and decision-support system for environmental civil protection services within the central Italian regions. A sensitivity study at different domain resolution and using different types of data to improve initial conditions has been performed by assimilating into the WRF model radar reflectivity measurements, collected by three C-band Doppler weather radars operational during the event that hit central Italy on 14 September 2012. The WRF assessment tools used are 3-D-Var and MET. The study is performed on the complex basin, both for the orography and physical phenomena, of the Mediterranean area. First of all, the WRF model responses to different types of cumulus parameterizations have been tested to establish the best configuration and to obtain the control simulation. The latter has been compared with observations and other experiments performed using 3-D-Var. The set of assimilation experiments have been conducted following two different strategies: (i) data assimilation at low and high resolution or at both resolutions simultaneously; (ii) conventional data against radar reflectivity data assimilation. Both have been examined to assess the impact on rainfall forecast.

The major findings of this work are the following:

- Grell 3-D parameterization improves the simulations both on D01 and D02 and the use of the spreading factor is an added value in properly predict heavy rainfall over inland of Abruzzo and the rainfall pattern along the northeast coast.

- Investigating the impact of the assimilation at different resolutions, positive results are shown by the experiments where the data assimilation is performed on both domains 12 and $3 \mathrm{~km}$. 
- The impact of the assimilation using different types of observations shows improvements if reflectivity from all the radars, along with SYNOP and TEMP are assimilated; furthermore, MM is the one that gives more optimistic results due to its excellent monitoring of the whole event.

- The outer loops strategy allows for further improving positive impact of the assimilation of multiple reflectivity radars data; moreover, a deeper investigation of this approach is required to assess its impact, above all concerning the running time in an operational context.

- We have seen that there are thresholds where the WRF $3-\mathrm{D}-\mathrm{Var}$ is statistically significant, with $95 \%$ confidence, while for other thresholds we have to be careful in drawing conclusions above all in the face of large uncertainty or when the score values are quite close to each other.

From the results obtained in this study, it is not possible to assess, in general terms, which is the best model configuration. In fact, this analysis should be performed systematically with a significant number of flash flood case studies before one can claim with certainty the positive impact of multiple reflectivity radar observations assimilation upon the forecast skill. Nevertheless, this work has pointed out aspects in 3-D-Var reflectivity data assimilation that encourages us to investigate more FFEs which have occurred over central Italy, in order to make the proposed approach suitable to provide a realistic prediction of possible flash floods both for the timing and localization of such events. To confirm and consolidate these initial findings, apart from analysing more case studies, a deeper analysis of the meteorology of the region and of the performance of the data assimilation system throughout longer trials in a "pseudo-operational" procedure is necessary. Moreover, a more sophisticated spatial verification technique (MODE, Method for Object-Based Diagnostic Evaluation; Davis et al., 2006a, b) which focuses on the realism of the forecast, by comparing features or "objects" that characterize both forecast and observation fields, could be investigated in the future. In fact, spatial verification methods are particularly suitable to address the model capability to reproduce structures like the convective systems responsible for the high precipitation events as considered in the present research, which, because of their typical dimensions, need high-resolution simulations to be predicted (Gilleland et al., 2009). These new-generation spatial verification methods, through the identification and the geometrical description of "objects" in forecast and observation fields (e.g. accumulated precipitation or radar reflectivity), permit an evaluation of the forecast skill in a more consistent way.

Data availability. The authors declare that the underlying research data generated and/or analysed during the current study are only partially publicly accessible, with some of them are available on request: for the analyses and conventional observations please contact ECMWF, for radar data please refer to their specific owner, and for rain gauges data please get in touch with the National Civil Protection Department and CIMA Research Foundation.

Competing interests. The authors declare that they have no conflict of interest.

Acknowledgements. We are grateful to the Gran Sasso National Laboratories for support in computing resources, as well as the National Civil Protection Department and CIMA Research Foundation for rain gauge data used for the model validation. NCAR is also acknowledged for the WRF model, the 3-D-Var system, and the MET tool. This work aims at contributing to the HyMeX programme.

Edited by: Hannah Cloke

Reviewed by: two anonymous referees

\section{References}

Barker, D. M., Huang, W., Guo, Y.-G., and Bourgeois, A.: A threedimensional variational (3-D-Var) data assimilation system for use with MM5, NCAR Tech. Note, NCAR/TN-453+STR, UCAR Communications, Boulder, CO, 68 pp., 2003.

Barker, D. M., Huang, W., Guo, Y.-R., Bourgeois, A., and Xiao, Q.: A three-dimensional variational (3-D-Var) data assimilation system for use with MM5: implementation and initial results, Mon. Weather Rev., 132, 897-914, 2004.

Daley, R.: Atmospheric Data Analysis, Cambridge University Press, Cambridge, UK, 1991.

Das, M. K., Chowdhury, M. A. M., Das, S., Debsarma, S. K., and Karmakar, S.: Assimilation of Doppler weather radar data and their impacts on the simulation of squall events during premonsoon season, Nat. Hazards, 77, 901-931, https://doi.org/10.1007/s11069-015-1634-9, 2015.

Davis, A. C., Brown, B., and Bullock, R.: Object-Based verification of precipitation forecasts, Part I: Methodology and application to mesoscale rain areas, Mon. Weather Rev., 134, 1772-1784, 2006 .

Davis, A. C., Brown, B., and Bullock, R.: Object-Based verification of precipitation forecasts, Part II: Application to convective rain system, Mon. Weather Rev., 134, 1785-1795, 2006 b.

Davolio, S., Ferretti, R., Baldini, L., Casaioli, M., Cimini, D., Ferrario, M. E., Gentile, S., Loglisci, N., Maiello, I., Manzato, A., Mariani, S., Marsigli, C., Marzano, F. S., Miglietta, M. M., Montani, A., Panegrossi, G., Pasi, F., Pichelli, E., Pucillo, A., and Zinzi, A.: The role of the Italian scientific community in the first HyMeX SOP: an outstanding multidisciplinary experience, Meteorol. Z., 24, 261-267, 2015.

Developmental Testbed Center: MET: Version 4.1 model evaluation tools users guide, 226 pp., available at: http://www.dtcenter.org/ met/users/docs/overview.php (last access: June 2017), 2013.

Diodato, N. and Bellocchi, G. (Editors.): Storminess and Environmental Change, in: Advances in Natural and Technological 
Hazards Research, 39, Springer Science+Business Media, Dordrecht, 1-283, 2014.

Dixon, M., Li, Z., Lean, H., Roberts, N., and Ballard, S.: Impact of data assimilation on forecasting convection over the United Kingdom using a high-resolution version of the Met Office Unified Model, Mon. Weather Rev., 137, 1562-1584, 2009.

Doswell, C.A. III., Brooks, A. E., and Maddox, R. A.: Flash flood forecasting: an ingredients-based methodology, Weather Forecast., 11, 560-581, 1996.

Ducrocq, V., Braud, I., Davolio, S., Ferretti, R., Flamant, C., Jansà, A., Kalthoff, N., Richard, E., Taupier-Letage, I., Ayral, P.A., Belamari, S., Berne, A., Borga, M., Boudevillain, B., Bock, O., Boichard, J.-L., Bouin, M.-N., Bousquet, O., Bouvier, C., Chiggiato, J., Cimini, D., Corsmeier, U., Coppola, L., Cocquerez, P., Defer, E., Delanoë, J., Di Girolamo, P., Doerenbecher, A., Drobinski, P., Dufournet, Y., Fourrié, N., Gourley, J. J., Labatut, L., Lambert, D., Le Coz, J., Marzano, F. S., Molinié, G., Montani, A., Nord, G., Nuret, M., Ramage, K., Risøn, B., Roussot, O., Said, F., Schwarzenboeck, A., Testor, P., Van-Baelen, J., Vincendon, B., Aran, M., and Tamayo, J.,: HyMeX-SOP1, the field campaign dedicated to heavy precipitation and flash flooding in the northwestern Mediterranean, B. Am. Meteorol. Soc., 95, 1083-1100, 2014.

Dudhia, J.: Numerical study of convection observed during the winter monsoon experiment using a mesoscale two-dimensional model, J. Atmos. Sci., 46, 3077-3107, 1989.

Efron, B. and Tibshirani, R. J.: An Introduction to the Bootstrap, Chapman and Hall, New York, 1993.

Ferretti, R., Pichelli, E., Gentile, S., Maiello, I., Cimini, D., Davolio, S., Miglietta, M. M., Panegrossi, G., Baldini, L., Pasi, F., Marzano, F. S., Zinzi, A., Mariani, S., Casaioli, M., Bartolini, G., Loglisci, N., Montani, A., Marsigli, C., Manzato, A., Pucillo, A., Ferrario, M. E., Colaiuda, V., and Rotunno, R.: Overview of the first HyMeX Special Observation Period over Italy: observations and model results, Hydrol. Earth Syst. Sci., 18, 1953-1977, https://doi.org/10.5194/hess-18-1953-2014, 2014.

Gilleland, E., Ahijevych, D., Brown, B. G., Casati, B., and Ebert, E. E.: Intercomparison of spatial forecast verification methods, Weather Forecast., 24, 1416-1430, 2009.

Ha, J.-H., Kim, H.-W., and Lee, D.-K.: Observation and numerical simulations with radar and surface data assimilation for heavy rainfall over central Korea, Adv. Atmos. Sci., 28, 573-590, https://doi.org/10.1007/s00376-010-0035-y, 2011.

Hertig, E., Paxian, A., Vogt, G., Seubert, S., Paeth, H., and Jacobeit, J.: Statistical and dynamical downscaling assessments of precipitation extremes in the Mediterranean area, Meteorol. Z., 21, 61-77, 2012.

Hsiao, L.-F., Chen, D.-S., Kuo, Y.-H., Guo, Y.-R., Yeh, T.-C., Hong, J.-S., and Fong, C.-T.: Application of WRF 3-DVAR to operational typhoon prediction in Taiwan: impact of outer loop and partial cycling approaches, Weather Forecast., 27.5, 12491263, https://doi.org/10.1175/waf-d-11-00131.1, 2012.

Ide, K., Courtier, P., Ghil, M., and Lorenc, A. C.: Unified notation for data assimilation: operational, sequential and variational, J. Meteorol. Soc. Jpn., 75, 181-189, 1997.

Italian Civil Protection Department and CIMA Research Foundation: The Dewetra Platform: A Multi-perspective Architecture for Risk Management during Emergencies. Springer International Publishing Switzerland, Chapter Information Systems for
Crisis Response and Management in Mediterranean Countries, Lect. Notes Bus. Inf., 196, 165-177, https://doi.org/10.1007/9783-319-11818-5_15, 2014.

Lee, J.-H., Lee, H.-H., Choi, Y., Kim, H.-W., and Lee, D.-K.: Radar data assimilation for the simulation of mesoscale convective systems, Adv. Atmos. Sci., 27, 1025-1042, https://doi.org/10.1007/s00376-010-9162-8, 2010.

Liu, J., Bray, M., and Han, D.: A study on WRF radar data assimilation for hydrological rainfall prediction, Hydrol. Earth Syst. Sci., 17, 3095-3110, https://doi.org/10.5194/hess-17-3095-2013, 2013.

Liu, Z.-Q. and Rabier, F.: The interaction between model resolution, observations resolution and observations density in data assimilation: a one-dimensional study, Q. J. Roy. Meteor. Soc., 128, 1367-1386, 2002

Llasat, M. C., Llasat-Botija, M., Petrucci, O., Pasqua, A. A., Rosselló, J., Vinet, F., and Boissier, L.: Towards a database on societal impact of Mediterranean floods within the framework of the HYMEX project, Nat. Hazards Earth Syst. Sci., 13, 13371350, https://doi.org/10.5194/nhess-13-1337-2013, 2013.

Lorenc, A. C.: Analysis methods for numerical weather prediction, Q. J. Roy. Meteor. Soc., 112, 1177-1194, 1986.

Maiello, I., Ferretti, R., Gentile, S., Montopoli, M., Picciotti, E., Marzano, F. S., and Faccani, C.: Impact of radar data assimilation for the simulation of a heavy rainfall case in central Italy using WRF-3DVAR, Atmos. Meas. Tech., 7, 2919-2935, https://doi.org/10.5194/amt-7-2919-2014, 2014.

Martín, J. R., García, M. M., de Dávila, F. P., and Soriano, L. R.: Severe rainfall events over the western Mediterranean Sea: a case study, Atmos. Res., 127, 47-63, 2013.

Nakatani, T., Misumi, R., Shoji, Y., Saito, K., Seko, H., Seino, N., Suzuki S.-I., Shusse, Y., Maesaka, T., and Sugawara, H.: Tokyo metropolitan area convection study for extreme weather resilient cities, B. Am. Meteorol. Soc., 96, ES123-ES126, 2015.

Parrish, D. F. and Derber, J. C.: The national meteorological center's spectral statistical-interpolation analysis system, Mon. Weather Rev., 120, 1747-1763, 1992.

Roberto, N., Adirosi, E., Baldini, L., Casella, D., Dietrich, S., Gatlin, P., Panegrossi, G., Petracca, M., Sanò, P., and Tokay, A.: Multi-sensor analysis of convective activity in central Italy during the HyMeX SOP 1.1, Atmos. Meas. Tech., 9, 535-552, https://doi.org/10.5194/amt-9-535-2016, 2016.

Sadiki, W., Fischer, C., and Geleyn, J.-F.: Mesoscale background error covariances: recent results obtained with the limited-area model ALADIN over Morocco, Mon. Weather Rev., 128, 3927 3935, 2000.

Salonen, K., Haase, G., Eresmaa, R., Hohti, H., and Järvinen, H.: Towards the operational use of Doppler Radar radial winds in HIRLAM, Atmos. Res., 100, 190-200, 2010.

Skamarock, W. C., Klemp, J. B., Dudhia, J., Gill, D. O., Barker, D. M., Duda, M. G., Huang, X.-Y., Wang, W., and Powers, J. G.: A description of the Advanced Reasearch WRF Version 3, NCAR Technical Note, TN 475+STR, 113 pp., available at: http://www2.mmm.ucar.edu/wrf/users/docs/arw_v3.pdf, last access: January 2012, 2008.

Sokol, Z.: Effects of an assimilation of Radar and satellite data on a very short range forecast of heavy convective rainfalls, Atmos. Res., 93, 188-206, 2009. 
Sokol, Z. and Rezacova, D.: Assimilation of Radar reflectivity into the LMCOSMO model with a high horizontal resolution, Meteorol. Appl., 13, 317-330, 2006.

Stanesic, A. and Brewester, K. A.: Impact of radar data assimilation on the numerical simulation of a severe storm in croatia, Meteorol. Z., 25, 37-53, 2016.

Sugimoto, S., Crook, N. A., Sun, J., Xiao, Q., and Barker, D. M.: An examination of WRF 3-D-VarRadar data assimilation on its capability in retrieving unobserved variables and forecasting precipitation through observing system simulation experiments, Mon. Weather Rev., 137, 4011-4029, https://doi.org/10.1175/2009MWR2839.1, 2009.

Sun, J. and Crook, N. A.: Dynamical and microphysical retrieval from Doppler RADAR observations using a cloud model and its adjoint, Part I: Model development and simulated data experiments, J. Atmos. Sci., 54, 1642-1661, 1997.

Sun, J. Xue, M., Wilson, J. W., Zawadzki, I., Ballard, S. P., OnvleeHooimeyer, J., Joe, P., Barker, D. M., Li P- W., Golding, B., $\mathrm{Xu}, \mathrm{M}$., and Pinto, J.: Use of NWP for nowcasting convective precipitation, recent progress and challenges, B. Am. Meteorol. Soc., 95, 409-426, 2014.

Thompson, G., R. M. Rasmussen, and Manning, K.: Explicit forecasts of winter precipitation using an improved bulk microphysics scheme, Part I: Description and sensitivity analysis, Mon. Weather Rev., 132, 519-542, 2004.
Vulpiani, G., Pagliara, P., Negri, M., Rossi, L., Gioia, A., Giordano, P., Alberoni, P. P., Cremonini, R., Ferraris, L., and Marzano, F. S.: The Italian radar network within the national early-warning system for multi-risks management, Proc. of Fifth European Conference on Radar in Meteorology and Hydrology (ERAD 2008), Finnish Meteorological Institute, Helsinki, 30 June-4 July 2008, 184, 2008.

Vulpiani, G., Baldini, L., and Roberto, N.: Characterization of Mediterranean hail-bearing storms using an operational polarimetric X-band radar, Atmos. Meas. Tech., 8, 4681-4698, https://doi.org/10.5194/amt-8-4681-2015, 2015.

Xiao, Q. and Sun, J.: Multiple-RADAR data assimilation and shortrange quantitative precipitation forecasting of a squall line observed during IHOP_2002, Mon. Weather Rev., 135, 3381-3404, 2007.

Xiao, Q., Kuo, Y.-H., Sun, J., and Lee, W.-C.: Assimilation of Doppler RADAR Observations with a Regional 3-D-Var System: Impact of Doppler Velocities on Forecasts of a Heavy Rainfall Case, J. Appl. Meteorol., 44, 768-788, 2005. 